Doi: www.doi.org/10.25130/tjaes.17.55.1.3

\title{
تأثثير الرقابة الداخلية وفقاً لإطار COSO المتكامل في تحسين تقارير الاستدامة لشركات النفط العراقية
}

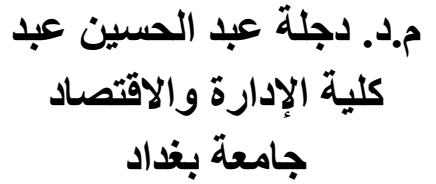

dijlahabd@gmail.com

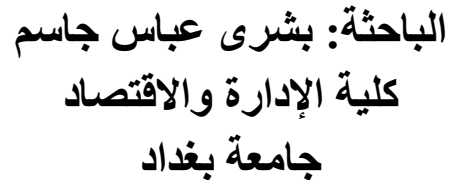

albagdadyabushra82@gmail.com

المستخلص: - ا:

اصبح التوجه نحو اعداد تقارير الاستدامة ضرورة ملحة تتحمل عبئها الوحدات الاقتصادية

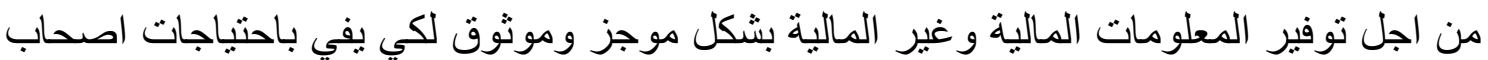

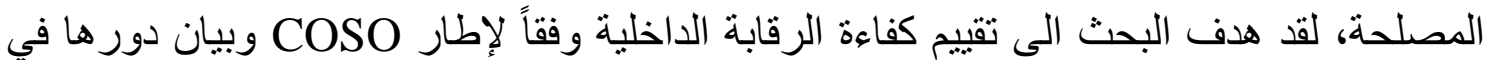
تحسين تقارير الاستدامة، ولتحقيق اهداف البحث واختبار فرضياته، تم تصميم استمارة الاستبيان التي تضمنت إعداد تقارير الاستدامة المعدل وفقاً لتوصيات إطار (COSO) المتكامل لسنة 2013 لذا فقد تم استخدامها لتمثل المتغير التابع وكذلك استمارة فحص التي تم من خلالها قياس مدى استناد الرقابة الداخلية للشركات عينة البحث على مبادئ مكونات الرقابة الداخلية وفق إطار (COSO)

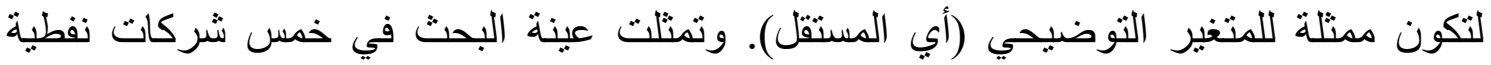
(شركة نفط الوسط، شركة توزيع المنتجات النفطية، شركة مصافي الوسط، شركة خطوط الانابئيب النفطية والثركة العامة لتعبئة وخدمات الغاز) وتم توزيع الاستبانة على مسؤولين في مر اكز

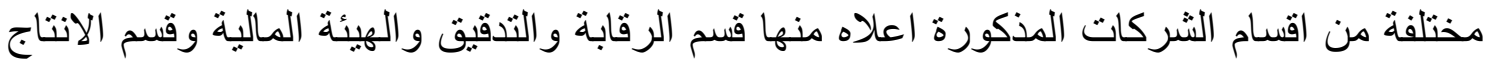
وقسم البيئة والسلامة. وتوصل البحث الى ان هناك تأثثير لأليات الرقابة الداخلية المستندة على الثى

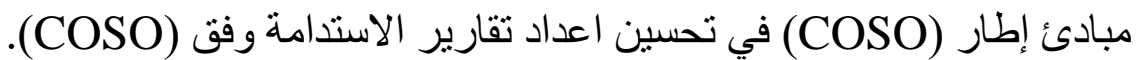

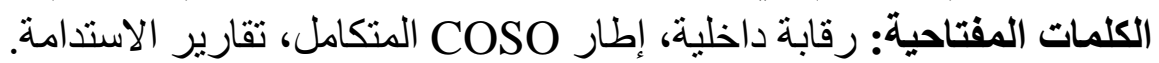

\section{The impact of internal control in accordance with the COSO Integrated Framework in improving sustainability reporting for Iraqi oil companies}

Researcher: Bushra Abbas Jassim

College of Administration and Economics

University of Baghdad
Lecturer Dr. Dijlah Abdul-Hussein Abd

College of Administration and Economics

University of Baghdad

\section{Abstract:}

The orientation towards preparing sustainability reports has become an urgent necessity that economic units bear in order to provide financial and non-financial information in a concise and reliable manner in order to meet the needs of stakeholders. The research aimed to evaluate the efficiency of internal control in accordance with the COSO framework and its role in improving sustainability reports, and to achieve research and testing objectives. His hypotheses, the questionnaire form that included preparing the modified sustainability reports was designed according to the recommendations of the 2013 Integrated Framework (COSO), so it was used to 
represent the dependent variable, as well as an examination form in which the extent of the reliance of the internal control of companies. (COSO) to be representative of the explanatory (i.e., independent) variable. The research sample was represented in five oil companies (Middle Oil Company, Oil Products Distribution Company, Middle Refineries Company, Oil Pipelines Company and the General Company for Gas Filling and Services). The questionnaire was distributed to officials in various centers of the above-mentioned companies' departments, including the Control and Audit Department and the Financial Commission. And the production department and the environment and safety department. The research found that there is an impact of internal control mechanisms based on the principles of the (COSO) framework in improving the preparation of sustainability reports according to (COSO).

Keywords: Internal control, integrated COSO frame, sustainable development reports.

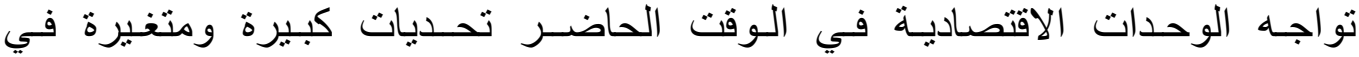
النواحي الاقتصادية والاجتماعية والبيئية، لذلك نادت المنظمات المهنية الدولية بضرورة التورة التزام الوحدات الاقتصادية بأعداد تقارير الاستدامة من اجل تجنب التأثيرات السلبية الناتجة عن انشطتها

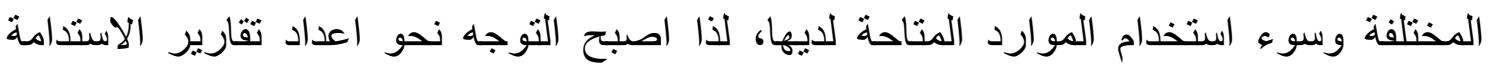

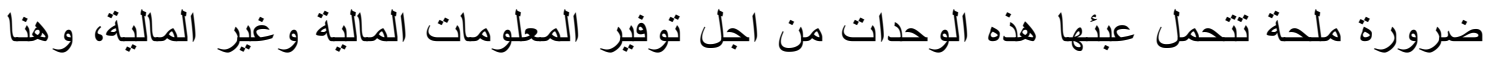
تلعب هذه الوحدات دوراً جوهرياً في تحقيق التنمية المستدامة من خلال أدر الك تأثير أنشطتها على فئى المجتمع، وعليه لابد لها من التعاون في أستغلال الفرص المتاحة لتجنب ايذاء الانسان و البيئة وتعظيم قيمة الوحدة في ذات الوقت بما بتلاءم مع طموحات أصحاب المصلحة، ومن هذه الفرص الفاص

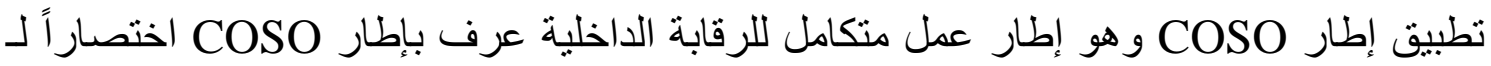
(Committee of Sponsoring Organizations) و التوجيهات بثأن ادارة المخاطر و الرقابة الداخلية والمحافظة على البيئة وتحمل المسؤولية الاجتماعية، وكل ذلك يثير الى العدالة في تلبية احتياجات الجيل الحالي مع المحافظة على احتياجات الاجيال القادمة وتحقيق التوازن بين التنمية الاقتصادية و الاجتماعية و البيئية.

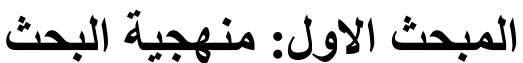

أولا. مشكلة البحث: هناك مبادر ات دولية مستمرة و التي تلزم الوحدات الاقتصادية بضرورة منهة اعداد تقارير الاستدامة وذلك لإدامة الجوانب الاقتصادية و الاجتماعية و البيئية، و عليه فأن مشكلة البحث

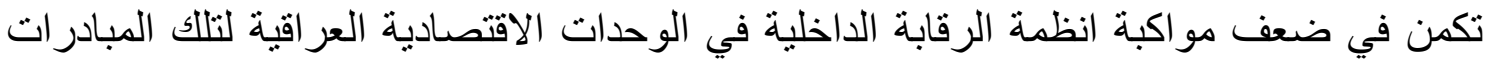
و الإصدار ات وتحديثاتها وهذا يؤثر بشكل كبير على ادائها وكفاءتها مما ينعكس سلبا على موقفها

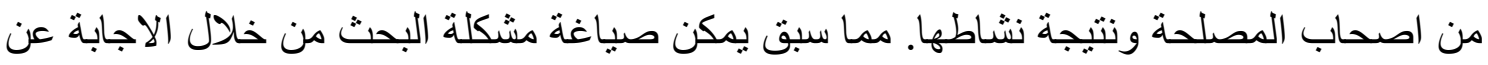
التساؤل الاتي: ما مدى تأثير تبني إطار COSO المتكامل وتحديثاته على انظمة الرقابة الداخلية

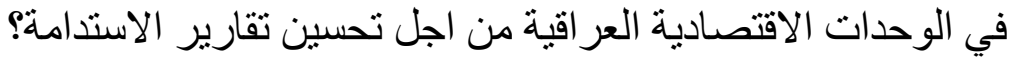

ثانياً. اهمية البحث: تكمن اهمية البحث كونه بسعى الىى بيان تأثير الرقابة الداخلية وفقاً لإطار COSO المتكامل ومكوناته في تحسين تقارير الاستدامة في شركات النفط العر اقية.

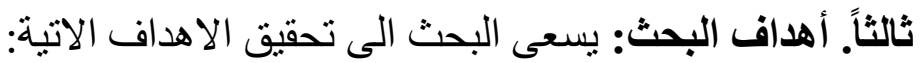
ا ـ توضيح مفهوم إطار COSO ومكوناته وتأثثيره في تقارير الاستدامة. 
r. توضيح تأثثير تبني إطار COSO ومكوناته على انظمة الرقابة الداخلية لثركات النفط العر اقية

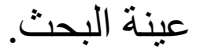
r. بيان دور الرقابة الداخلية وفق إطار COSO المتكامل في تحسين اعداد تقارير الاستدامة في عينة من الثركات النفطية العر اقية. رابعاً. فرضية البحث: يبنى البحث على الفئه فرضيتين رئيسيتين هما: (H1) الفرضية الرئيسة الاولى: هنالك تأثير لأليات الرقابة الداخلية المستندة على مبادئ إطار

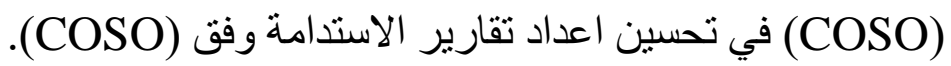
(H2) الفرضية الرئيسة الثانية: هناك تأثير لأليات الرقابة الداخلية المستندة على مبادئ إطار

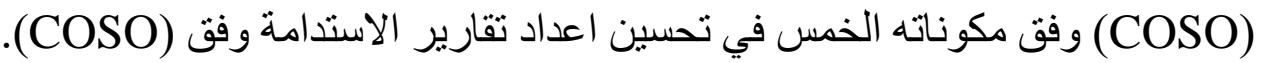
تتفرع هذه الفرضية إلى خمس فرضيات فرعية بحسب اعلى المكونات الخمس لإطار (COSO)

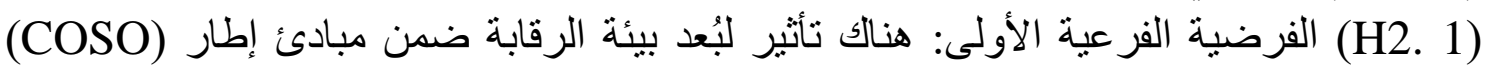

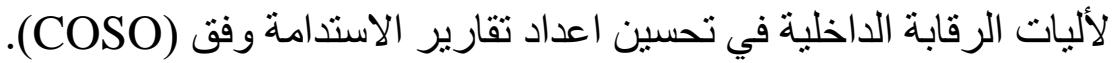

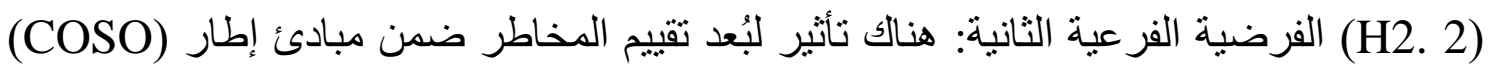

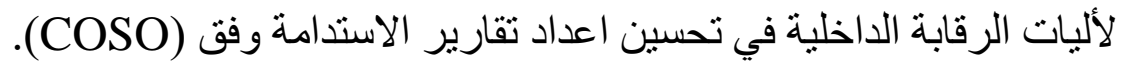

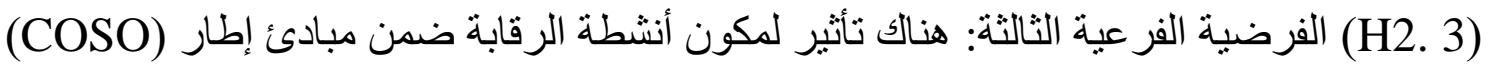

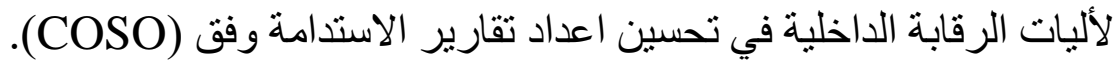

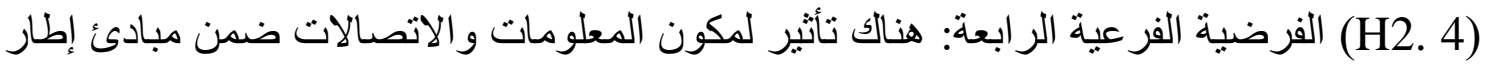

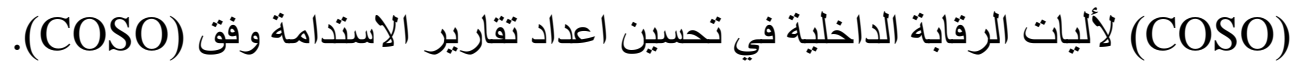
(H2. 5)

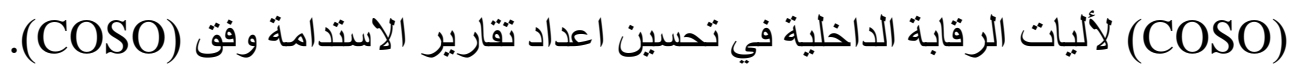

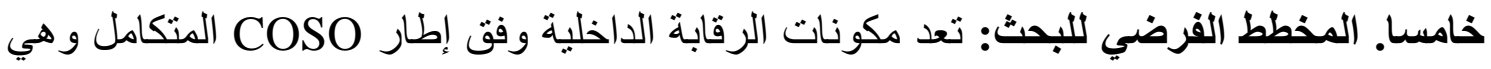

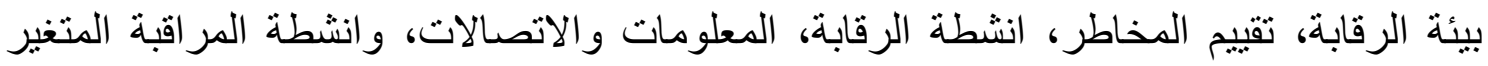

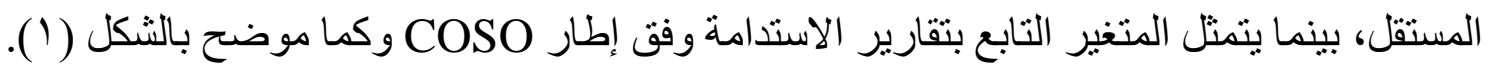

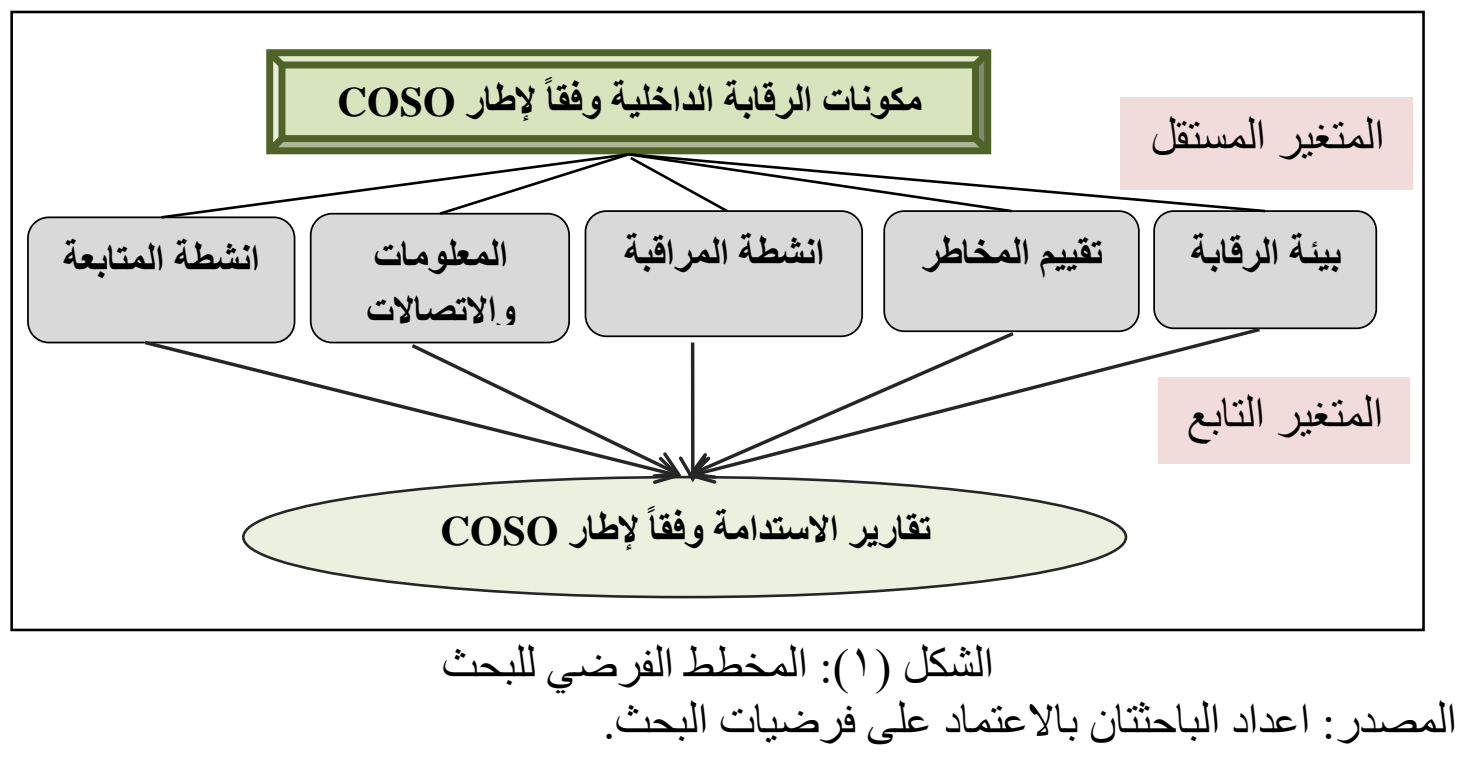


سادسا. الادوات الاحصائية المستخدمة في البحث: تم معالجة بيانات هذا البحث باستخدام البرنامج الإنة

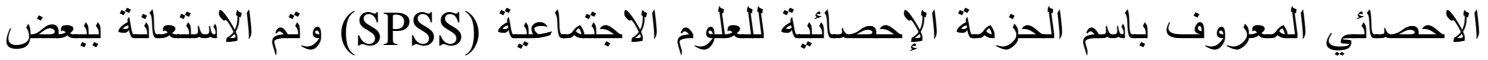
الأدو ات الإحصائية أهمها:

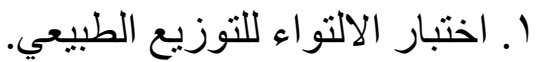

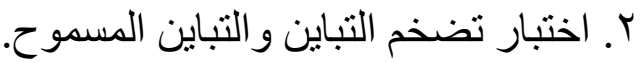
؟ـ معامل الارتباط بيرسون: تم استخدامه لتحديد طبيعة العلاقة بين المتغير المستقل و المتغير التابع.

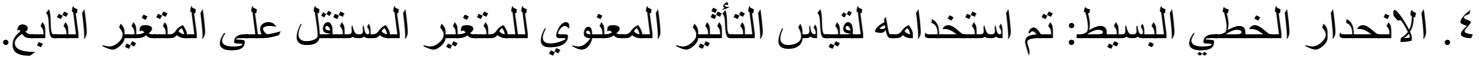
سابعا. اداة قياس البحث: استخدمت استمارة فحص (checklist) لجمع البيانات اللازمة لفحص الرقابة الداخلية وفقاً لإطار COSO المتكامل، وكذلك استخدمت استمارة استبيان لجمع البيانات

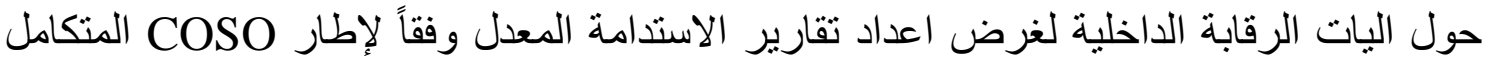

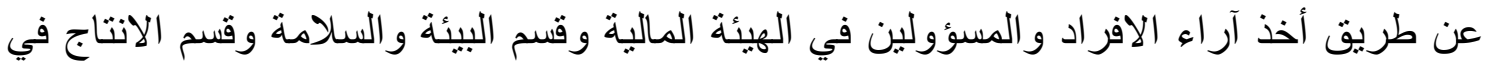

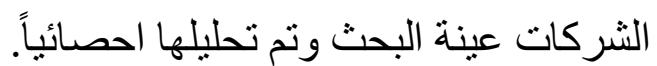
ثامناً. مجتمع وعينة البحث: تمثلت الحدود المكانية لعينة البحث في خمس شركات (شركة نفط الوسط، وشركة توزيع المنتجات النفطية، شركة مصافي الوسط شركة خطوط الانابيب النفطية

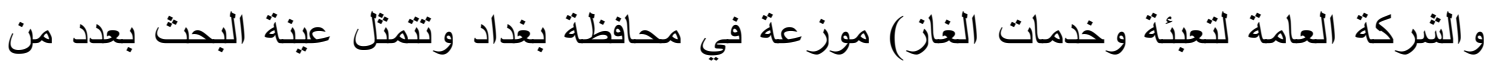

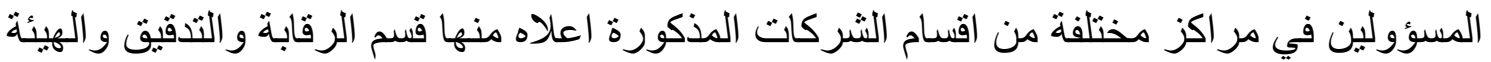

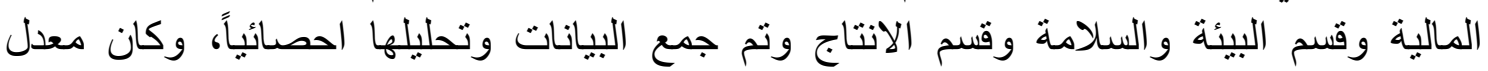

الاستجابة كما موضح بالجدول (1):

الجدول (1): عدد استمار ات الاستبيان الصالحة المستردة من الثركات عينة البحث

\begin{tabular}{|c|c|c|c|c|c|}
\hline الصالح & استبعاد الاجابات & مسترد & موزع & اسم الشركة & ت \\
\hline 18 & 0 & 18 & 20 & شركة نفط الوسط & 1 \\
\hline 18 & 0 & 18 & 20 & شركة توزيع المنتجات النفطية & 2 \\
\hline 17 & 0 & 17 & 20 & شركة مصافي الوسط & 3 \\
\hline 16 & 0 & 16 & 20 & شركة خطوط الانابيب النفطية & 4 \\
\hline 18 & 0 & 18 & 20 & الشركة العامة لتعبئة وخدمات الغاز & 5 \\
\hline 87 & 0 & 87 & 100 & الاجمالي & \\
\hline
\end{tabular}

الجدول من إعداد الباحثتان بالاعتماد على مخرجات البرنامج الاحصائي (SPSS). تاسعا. الحدود الزمانية: تمثلت الحدود الزمانية في السنة 2020.

\section{المبحث الثاني: إطار COSO المتكامل ودوره في اعداد تقاريز الاستدامة}

اولاً. مفهوم إطار COSO المتكامل: تم وَضع إطار عمل متكامل للرقابة الداخلية في سنة 1992 عُرف بإطار COSO، ويعني اللجنة الراعية للمنظمات المنبثقة عن تريدواي (Treadway)،

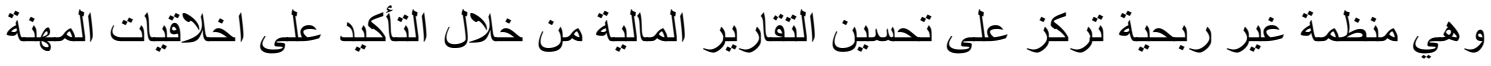
وتقوم بتمويلها خمس جمعيات من الفئة المهنية الرئيسة في المجال المالي في الولايات المين المتحدة وهي: (جمعية المحاسبة الأمريكية، المعهد الأمريكي للمحاسبين القانونبين، المدراء التنفيذيين 
الدوليين، جمعية المحاسبيين و المهنيين الماليين في مجال الأعمال التجارية، معهد المدققين (الداخليين). (Morelo, 2011: 25) بادرت اللجنة اعلاه بإصدار نسخة محدثة من الإطار المتكامل للرقابة الداخلية لعام 2013، اذ كانت

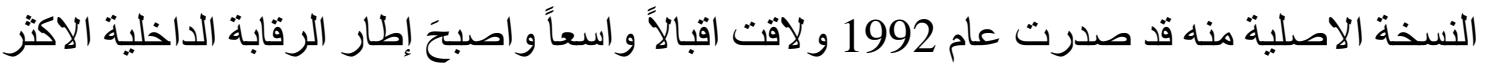

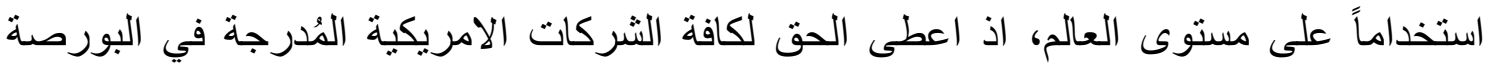

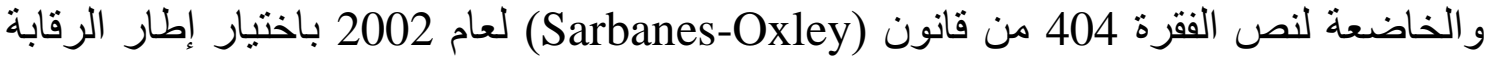

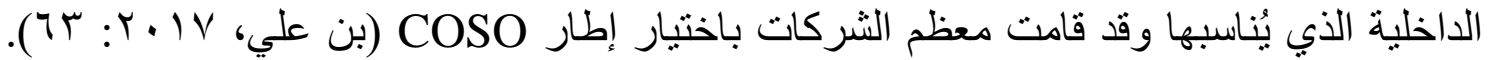

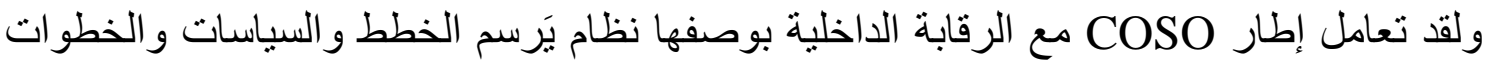

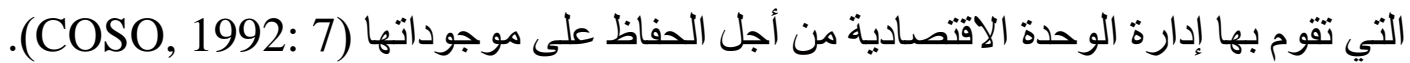

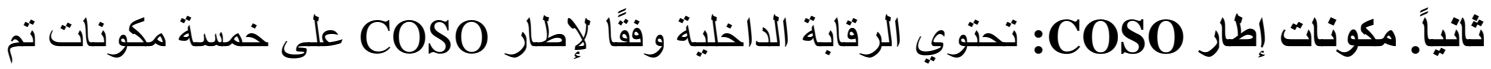
تصميمها وتتفيذها من قبل الإدارة لتسهم في تحقيق أهداف التهابة الرقابة. ويمكن تحديد هذه المكونات بما يأتي: (Arens et al., 2012:

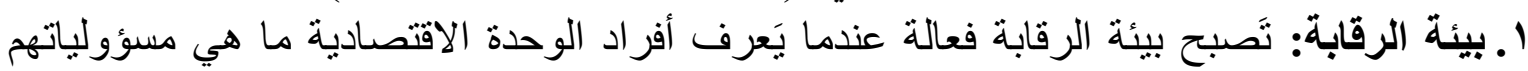

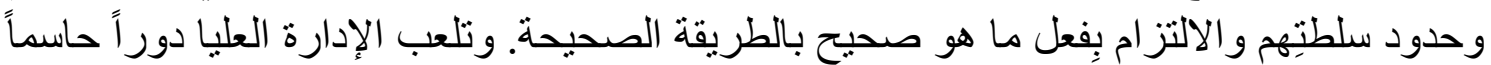

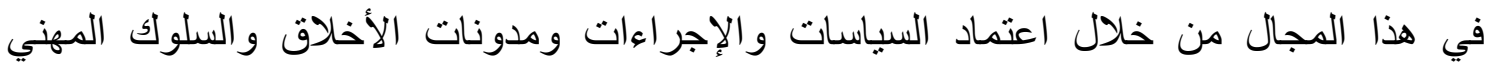
(Morelo, 2011: 27) r. تقييم المخاطر: ان وجود الأهداف هو شرط اساس لوجود رقابة داخلية وينبغي أن تكون واضحة

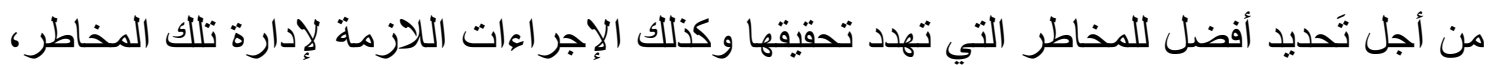

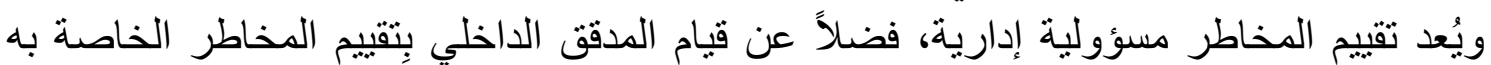

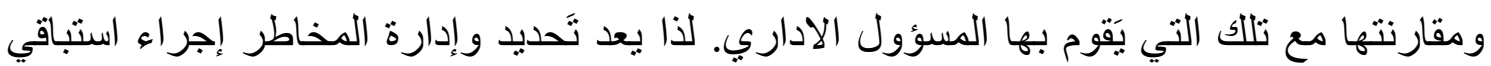

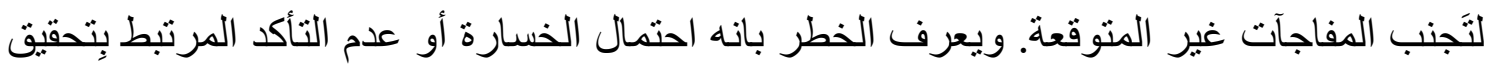

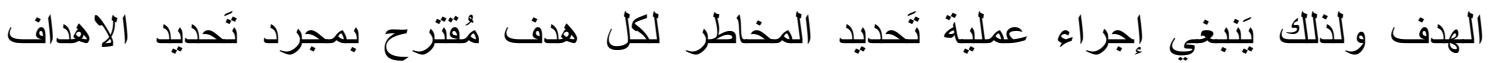

(Morelo, 2011: 28)

r. أنشطة الرقابة: تتمثل انشطة الرقابة بمجموعة من الاجراءات الرقابية التي تساعد في تحقيق الرقابق

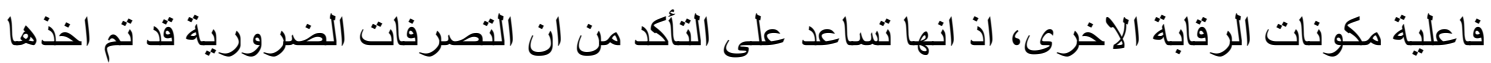

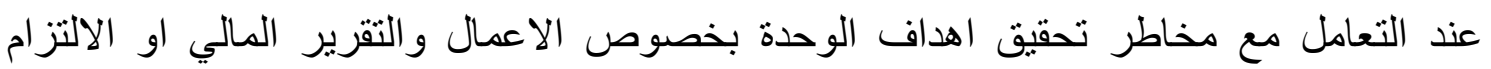

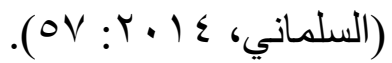
ع. المطومات والاتصالات: يوفر هذا المكون من إطار COSO اتصالاً بين العناصر الأربعة الأخرى

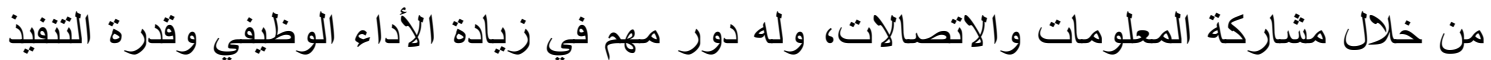

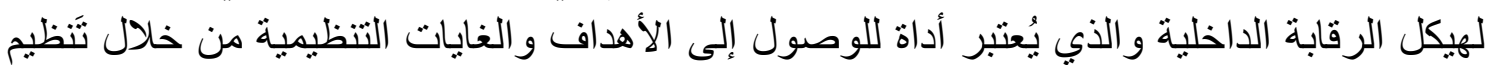

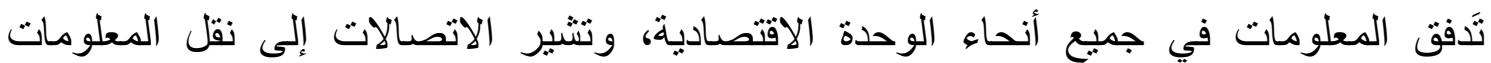

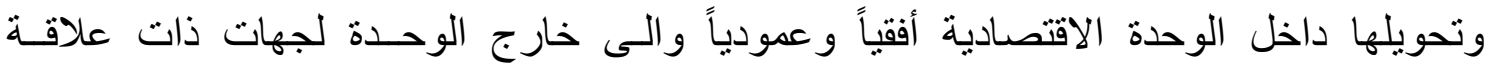

(Uzun, 2017: 25)

•ـ انشطة المتابعة: ان نشاط المتابعة هو تَقيم للرقابة الداخلية بمرور الوقت للتحقق مما إذا كانت الرقابة الداخلية ملائمة وفعالة، ويتم ذلك من خلال الملانهانة المظة المستمرة للأنشطة ومن خلال

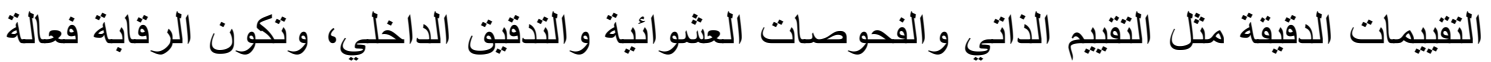


عندما يكون لدى الإدارة المركزية تأكيد معقول لدرجة تَحقيق الأهداف التشغيلية المقترحة، وأن المبان المعلومات الواردة في التقارير موثوق بها وأن القو انين و اللو ائح و المعايير ذات الات العلاقة يتم الامتثال لها (Morelo, 2011: 31).

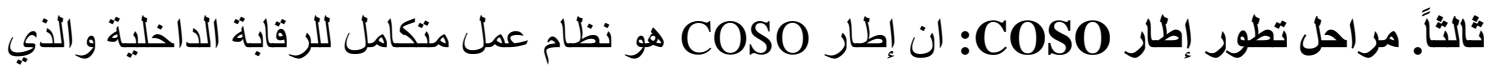

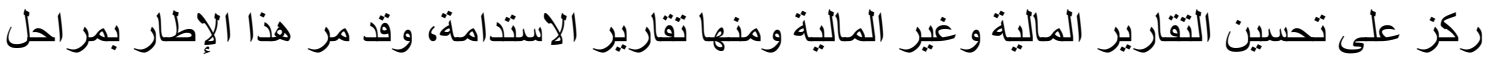

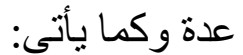

المرحلة الاولى: تَمَ إصدار تقرير إطار COSO النهائي عن الرقابة الداخلية في سنة 1992 تَحت

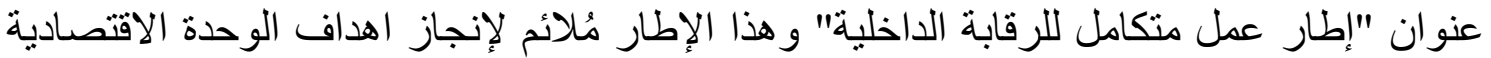

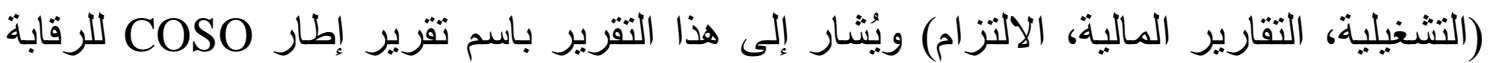

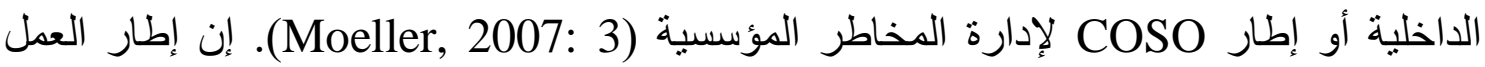

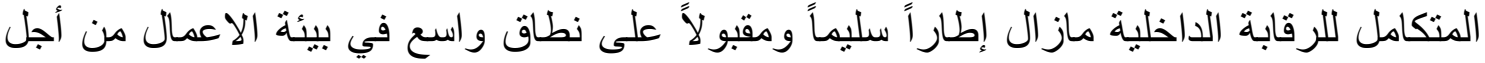

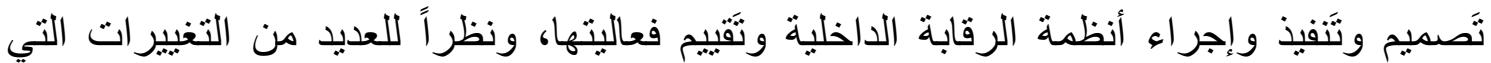

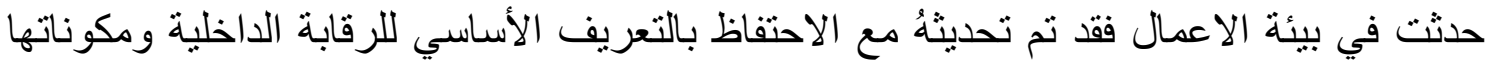

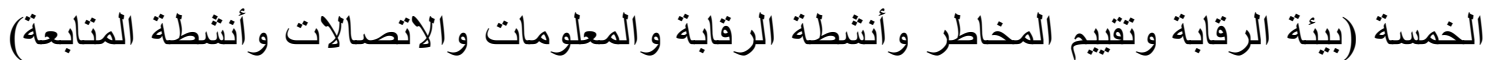

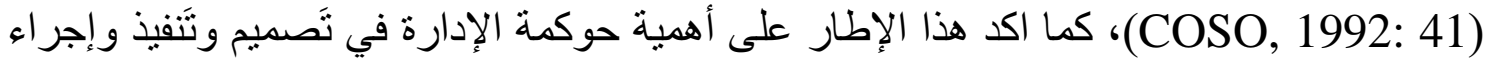

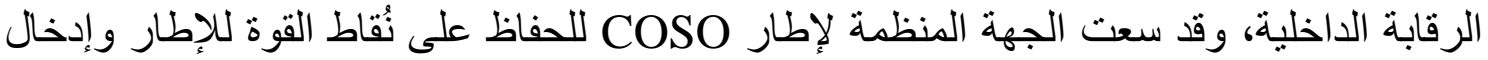

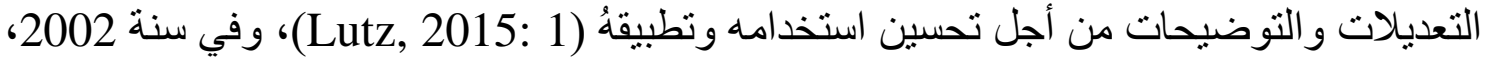

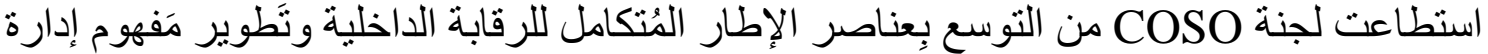

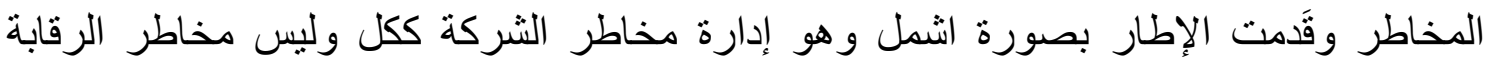
الداخلية فقط، لتتمكن الثركات من تَحسين إدارة المخاطر فيها (Thabit, 2019: 4).

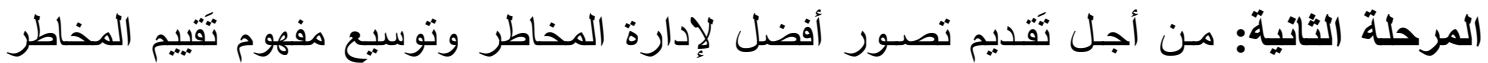

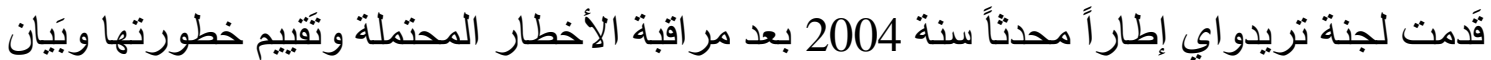

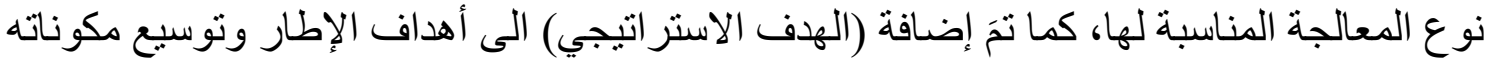

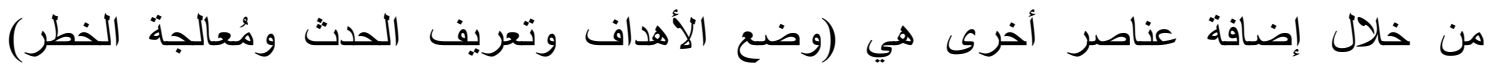
(Uwadiae, 2015: 37)، كما قدم الإطار تعريفاً لإدارة المخاطر على الإنى أنه الوظيفة التي يَتعاون

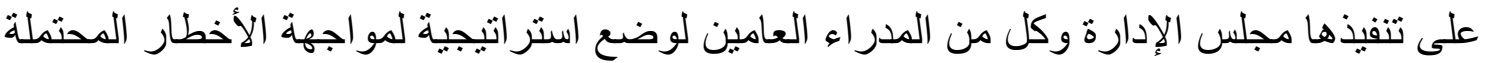

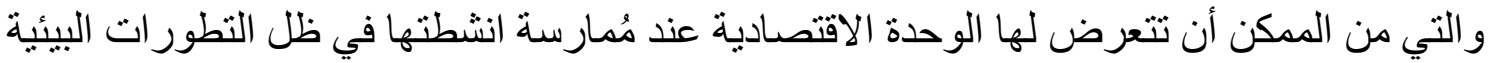

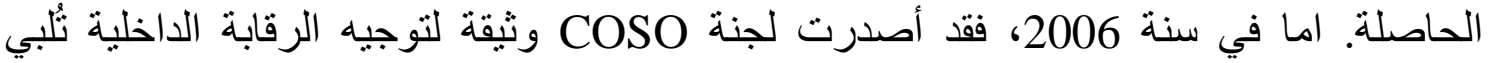

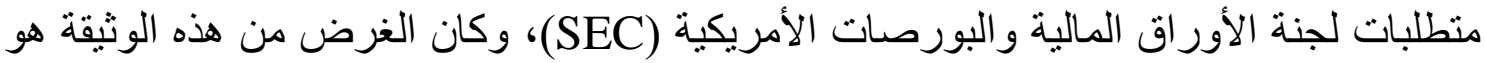

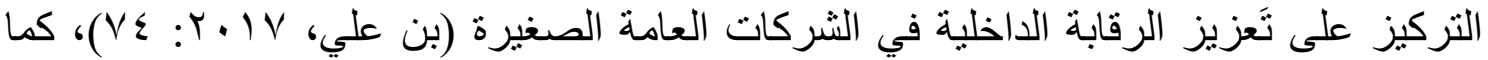

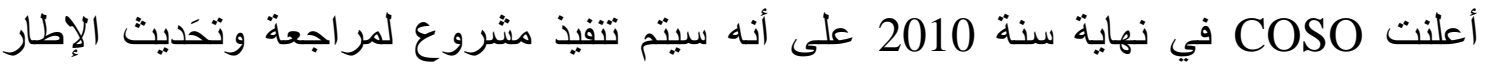

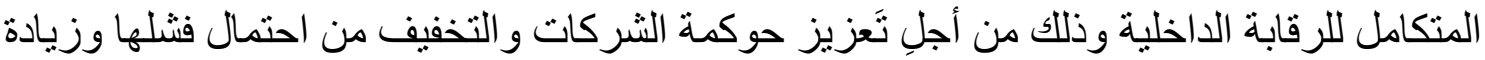

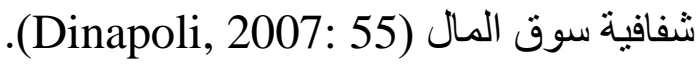
المرحة الثالثة: في سنة 2013، أصدرت لجنة COSO نسخة محثثة للإطار المتكامل للرقابة

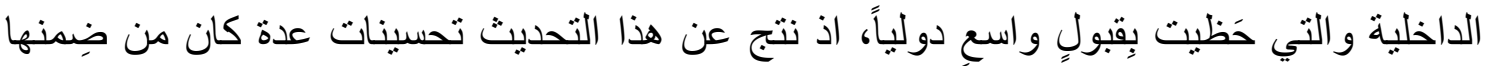

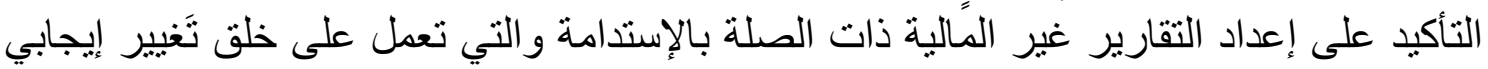




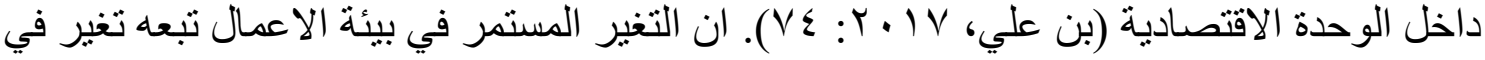
الانشطة و العمليات بشكل جذري وذللك بسبب التطور التكنولوجي مما جعل من هذا الإطار داعماً

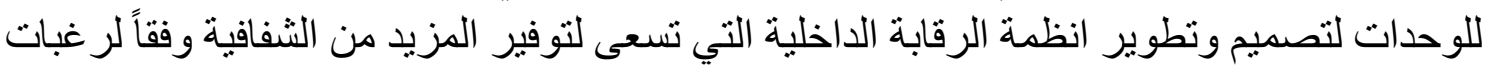

اصحاب المصلحة (Provasi, 2015: 490). لقد كانَ الهدف من تَحديث إطار COSO هو لتَسهيل تَطور نظم الرقابة الداخلية وتُقييم فعاليتها، لتَعكس العديد من التغيير ات في بيئات العمل والتشغيل على مدار العشرين سنة الماضية

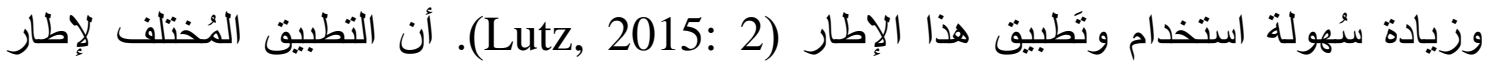
COSO

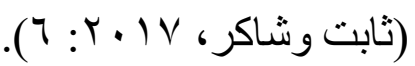
وقد أعلن مجلس COSO أنه سيستمر في العمل بإطار COSO العندة الأصلي خلال الفترة

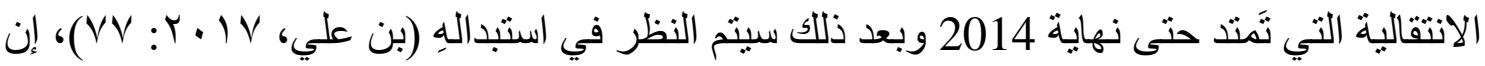

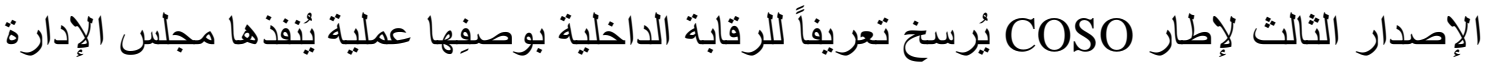

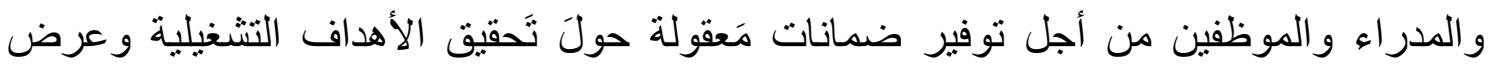

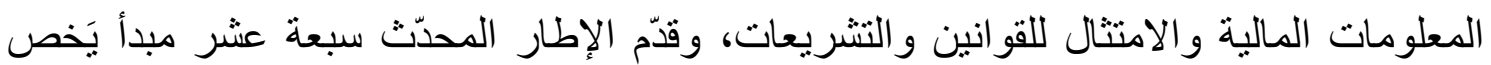

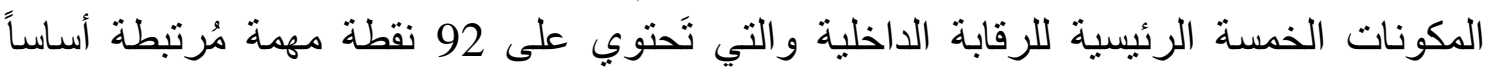

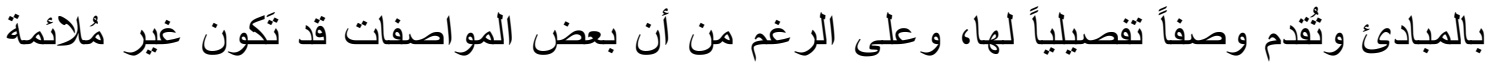

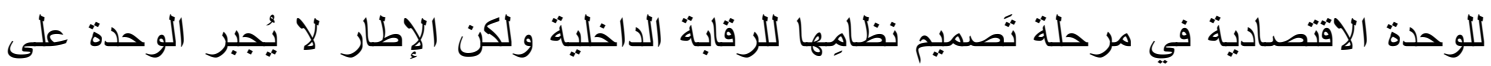

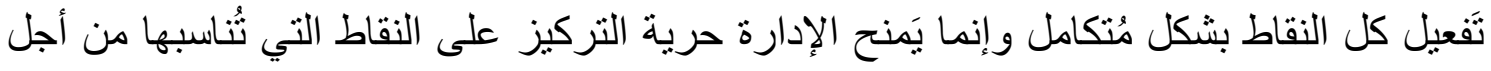
تَصميم نِظام رقابة فعّال (COSO, 2013: 124)، ولتحقيق ذلك ينبغي توفر المتطلبات الاتية:

(Lutz, 2015: 3)

1. كل عنصر من مكونات الرقابة الداخلية الخمسة و المبادئ ذات العلاقة موجود ويتم العمل بـه. Y. تعمل المكونات الخمسة معاً بطريقة مُنكاملة.

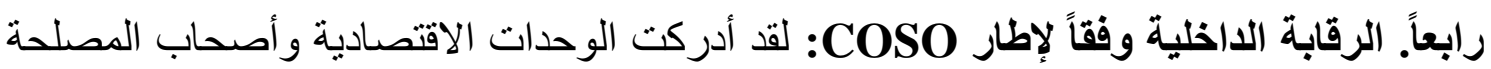

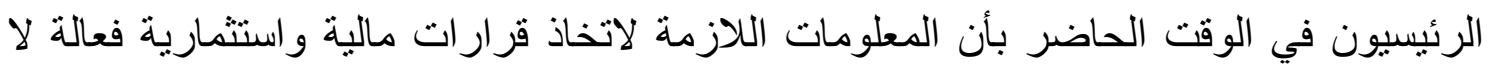

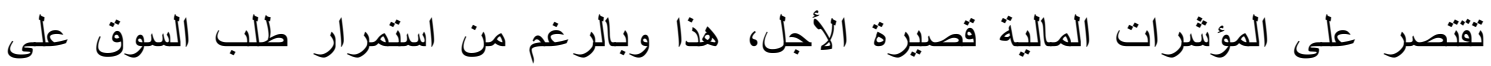

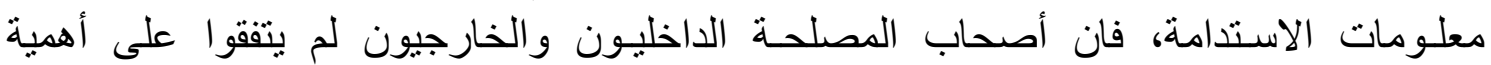
معلومات الاستدامة، وهذا يحد من فائدة وجودة المعلومات المتاحة في القوائم المالية التقليدية

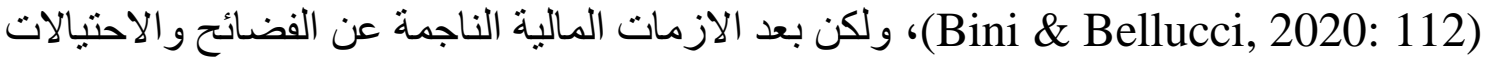
التي حصلت في الولايات المتحدة الامريكية، مما حدا بالعديد من المنظمات الدولية الى إصدار الصدار معايير وقو انين رادعة لها، وأحد أهم الاطر التي تم إصدار ها و التي تتظم دور الرقابة التهابة الداخلية في الوحدات الاقتصادية هو إطار COSO فهو يعزز من جودة المعلومات لمتخذي القرارات (Kinkela, 2015: 63)، لقد أوضح إطار COSO متطلبات نظام الرقابة الداخلية الفعال كونه

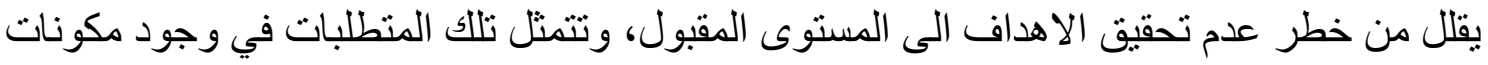
الرقابة الداخلية الخمس والمبادئ ذات العلاقة، وان وان تعمل تللك المكونات معاً بطريقة متكاملة (Lutz, 2015:3)، وتعامل إطار COSO مع الرقابة الداخلية بوصفها نظام يرسم السياسات و الخطط و الخطوات التي تقوم بها الوحدة من اجل الحفاظ على موجوداتها وتقديم تأكيد مقبول حول 
تحقيقها لأهدافها المتعلقة بالعمليات التشغيلية والعمل على اعداد تقارير الامتثال ومنها تقارير الاستدامة (COSO, 2013: 24)

خامساً. مفهوم وخصائص التنمية المستدامة: لقد اتجهت العديد من الوحدات الاقتصادية الى اتخاذ خطوات جادة أتجاه التنمية المستدامة التي وضعت أساسيها مفوضية الأمم المتحدة للتنمية والبيئة،

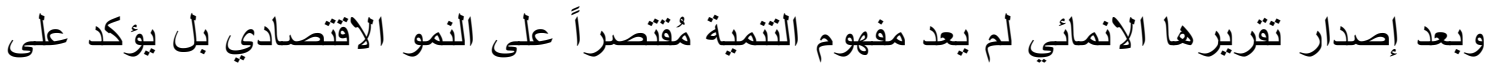

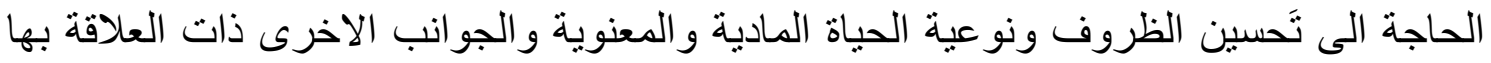

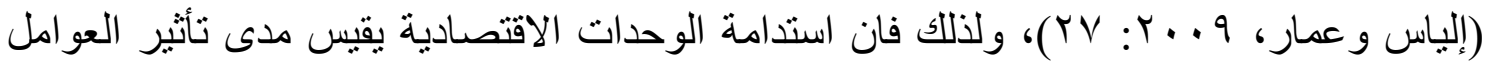

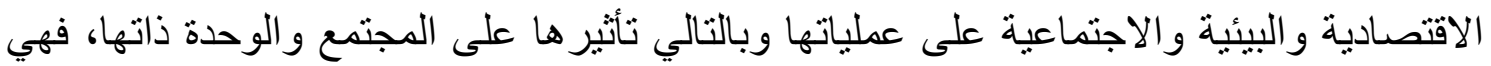
استر اتيجية الاعمال التي تهدف الى استخدام أفضل الممارسات بما بسهم في تحقيق التوازن بئ ولين

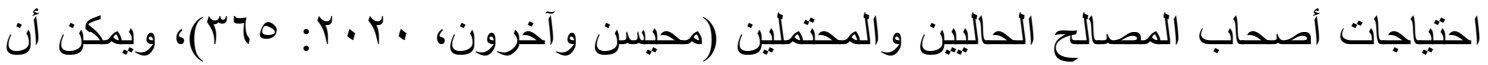

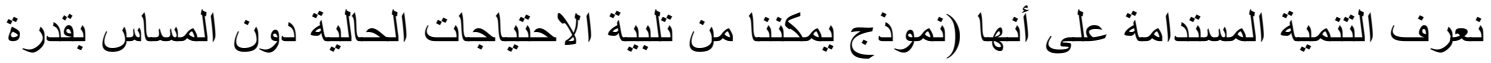

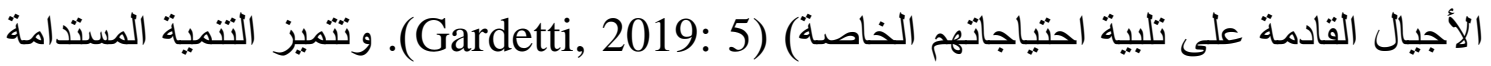

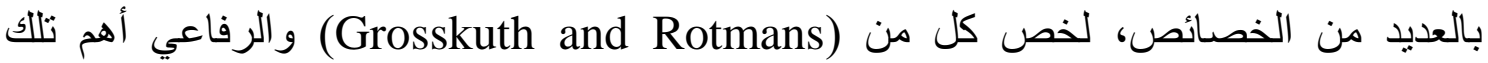

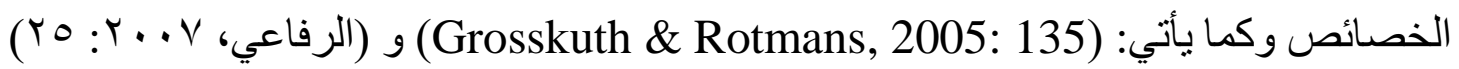
' ـ تنمية طويلة الأمد تقوم على البعد الزمني مع التركيز على مصير ومستقبل الأجيال القادمة.

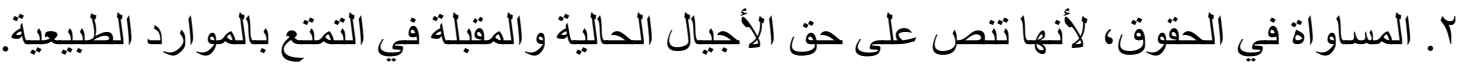
r. خطة مترابطة ومتعددة تقوم على التنسيق والتكامل بين أبعاد الاستدامة الاقتصادية والاجتماعية

و البيئية.

ع. للتنمية المستدامة بُعد دولي اذ يسعى المجتمع الدولي إلى تكثيف الجهود لمساعدة الدول الفقيرة.

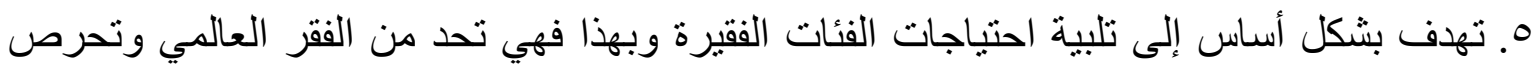

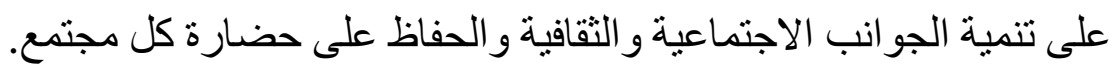

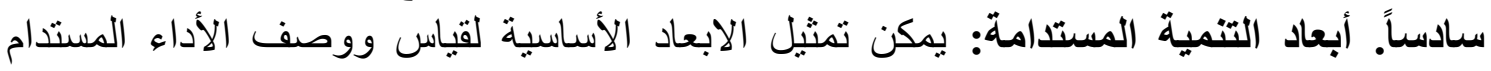

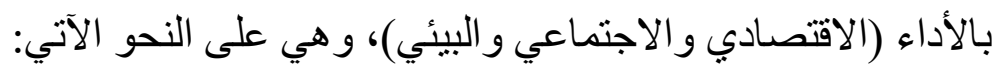

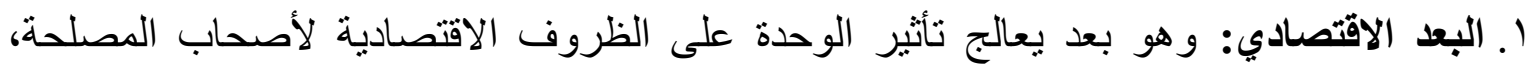

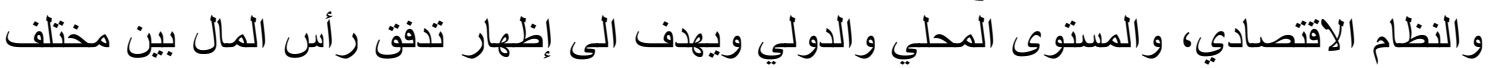
أصحاب المصلحة والأثر الاقتصادي للوحدة على المجتمع. كما يهدف إلى زيادة مستوى الرفاهية

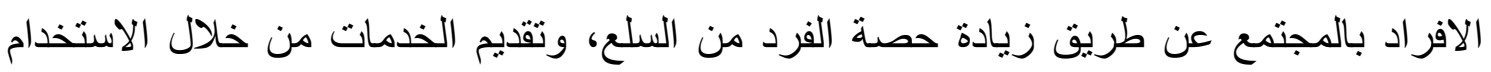

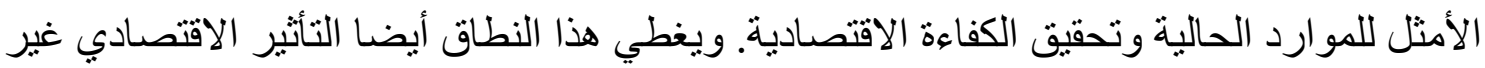

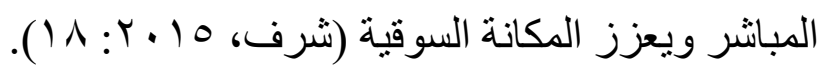

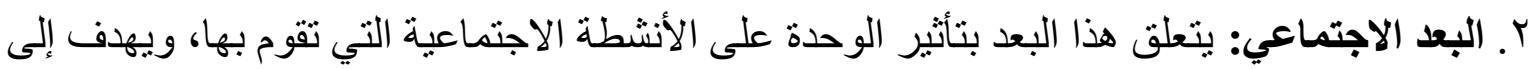

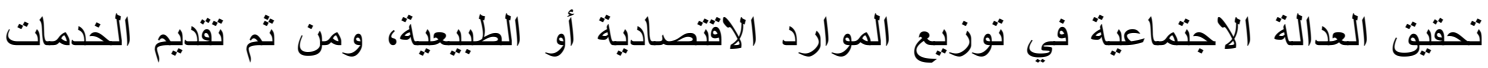

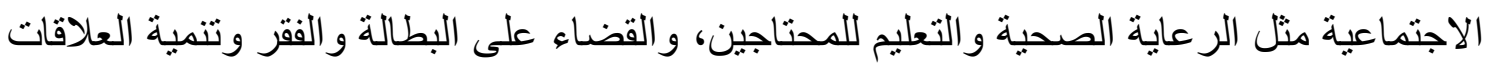
بين الوحدة من جهة و اصحاب المصلحة الداخليين والخارجيين من جهة اخرى، فهو يمثل البعد البهد الإنساني الذي يجعل النمو وسيلة للتكامل الاجتماعي لأنه يهتم بحق الإنسان للعيش في بيئة صحية هينة ونظيفة يمارس فيها جميع الأنثطة مع ضمان حقه في كافة الخدمات البيئية والاجتماعية و الموارد 
الطبيعية ويستثر ها بطرق تلبي احتياجاته الأساسية و المكملة لتحسين المستوى المعيشي له، دون

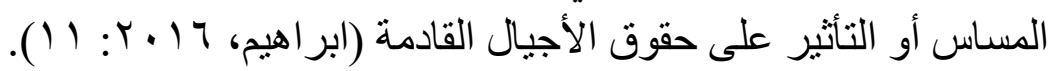

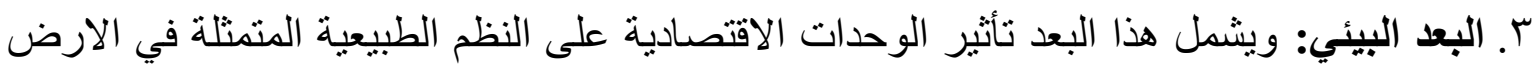
و الهو اء و الماء و الأنظمة البيئية، ويهدف وإلى الئى الاستخدام الأمثل للموارد الطبيعية وحمايتها وسلامتها من التلوث، لذلك من الضروري إدراء الك الارتباط بين ادارة الموارد البشرية والطبية الطية الطية لأن فهم

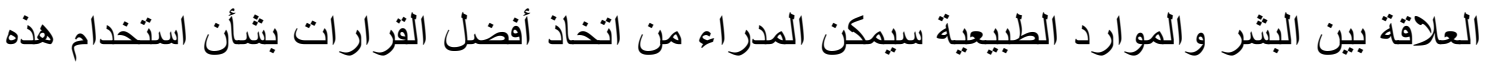

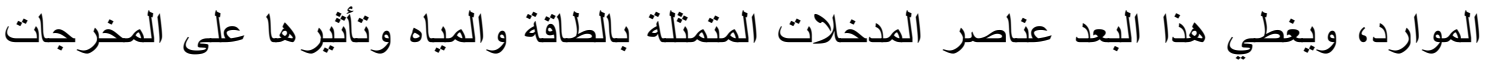

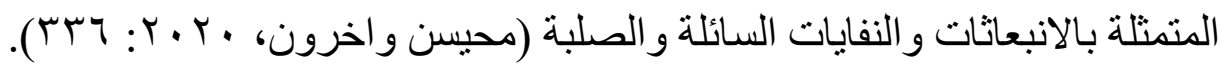

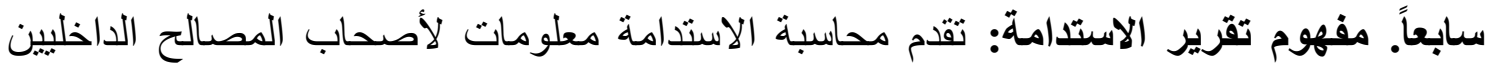

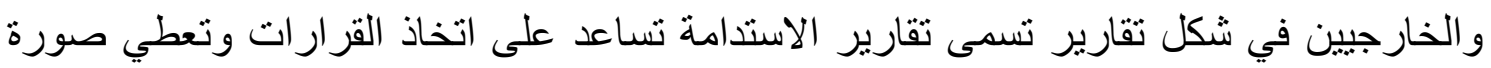

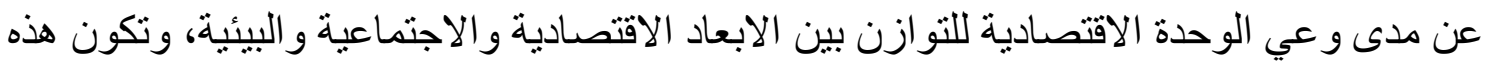
التقارير بشكل دوري، ويفضل ان تعد قبل عملية اتخاذ القرار،ويمكن أن تتشر معلمومات الاستدامة الأنة

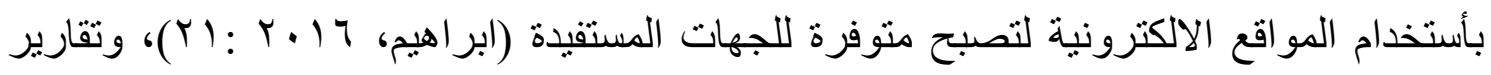
الاستدامة تعني قيام الوحدات الاقتصادية بدمج معلومات عن انشطتها الاقتصادية والاجتماعية والبيئية في قوائمها المالية او بصورة تقارير منفصلة للتعبير عن مسؤوليتها أتجاه المجتمع وتقييم

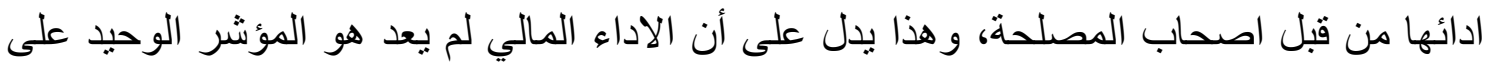

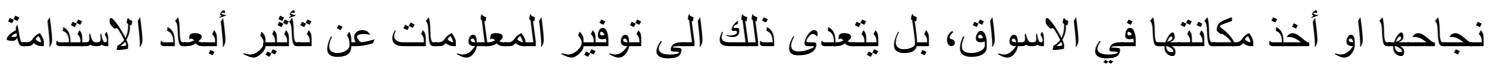

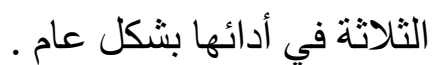
وتعرف تقارير الاستدامة على انها تقارير علنية تعد من قبل الوحدات الاقتصادية لتزويد اصحاب المصلحة الداخليين والخارجيين بصورة واضحة عن انشطتها الاقتصادية والبيئية

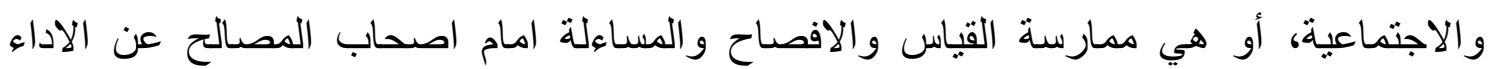
التظظيمي تجاه هدف التنمية المستدامة، و عليه فان تقارير الاستدامة بما تحويه من معلومات وات مالية و غير مالية عن أداء الوحدات الاقتصادية في أبعادها الثلاثة تمثل الادارة الفعالة في سد فجوة فئنة

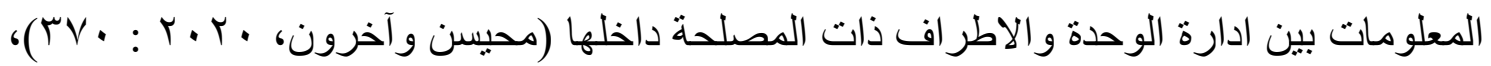
ولقد تم صياغة ووضع مؤشرات الاستدامة من فبل لجنة المبادرة العالمية لإعداد التقارير (GRI)

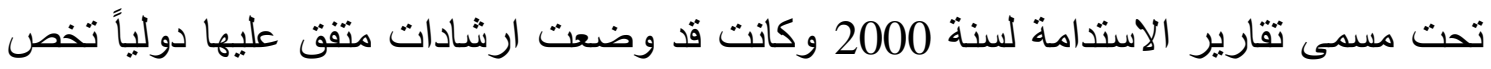

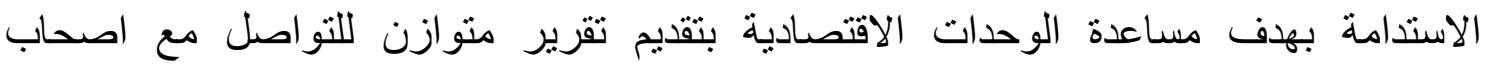

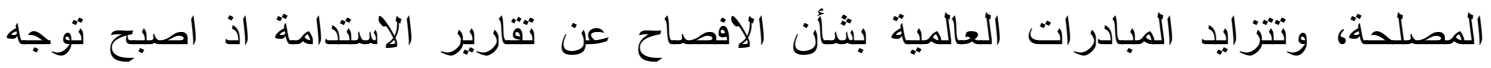
المستثرين نحو الوحدات التي تدمج في ستراتيجيتها عنصر الاستدامة بحيث لا يترتب عليها

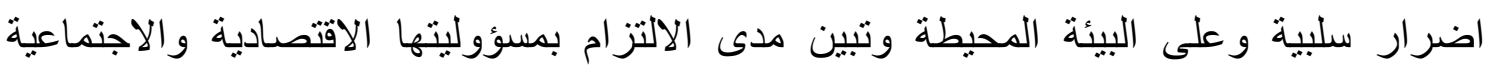

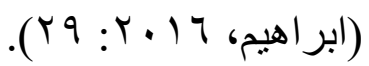
ثامناً. اعداد تقارير الاستدامة والعقبات التي تواجهها: ينبخي أن تحتوي تقارير الاستدامة على كل من المعلومات النوعية و الكمية التي تكثف عن اداء الوحدة وفاعليته للأنشطة الاقتصادية و والبيئية و الاجتماعية خلال فترة معينة وكيف يتم دمج هذه الجو انب في نظام و احد يسمى إدارة الاستدامة. 
إن هذه التقارير تعد أداة للتو اصل، فمن خلالها بمكن تقييم سياسة الاستدامة للوحدة بشكل

كامل (Zsoka, 2018: 21).

كما تعد هذه التقارير لقياس وكثف الاداء التنظيمي للتنمية المستدامة للوحدة الاقتصادية أمام أصحاب المصلحة الداخليين والخارجيين باستخدام المؤشرات المالية وغير المالية لتحقيق اهداف التنمية الثاملة (Idowu, et al., 2015: 101)، ويساعد تقرير الاستدامة الوحدات الاقتصادية على تحديد الأهداف وقياس الأداء و إدارة التغيير وذلك بأعداد تقارير الابلاغ عن الاثار

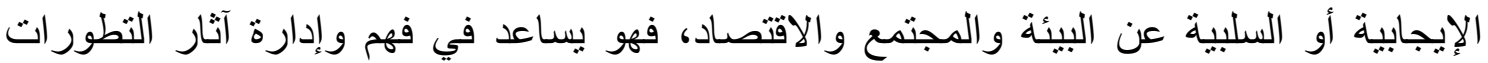

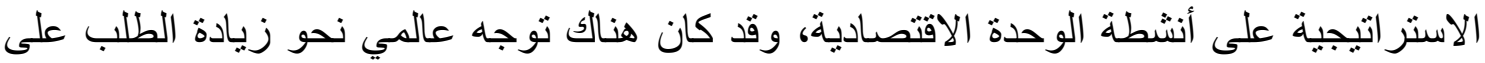
تقارير الاستدامة بسبب الاهتمام المنز ايد بالقضايا البيئية والاجتماعية (Mammatt, 2009: 15). ومن العقبات التي تو اجه إعداد تقارير الاستدامة هي: (Lee \& Herold, 2018: 23) ا ـ يتطلب اعداد تقرير الاستدامة جهداً و عملاً أكثر مما يتطلبهُ إعداد التقارير المالية.

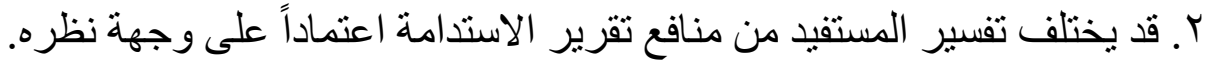
r. هنالك العديد من فقرات هذه التقارير تحتوي على معلومات لا يمكن قياسها لأنها تغطي فترات

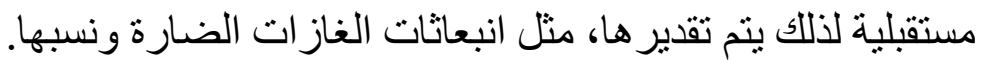
تاسعاً. تأثير تظبيق إطار الرقابة الاخلية COSO على تقارير الاستدامة: تقوم معظم الشركات

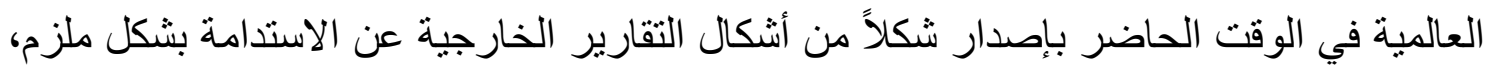
مثل إصدار تقارير الامتنال للوائح الاتحاد الأوروبي الجديدة، أو استجابة لمتطلبات الإدر اج الحديثة الخاصة بـ (Securities and Exchange Commission: SEC) وهي هيئة الاوراق المالية و البورصات، وفي حالة عدم وجود إلز ام، تقوم الثركات بإصدار تقارير الاستدامة بشكل طوعي هيته للاستجابة لمطالب أصحاب المصلحة، وان التنافس للحصول على رأس المال من المستثمرين

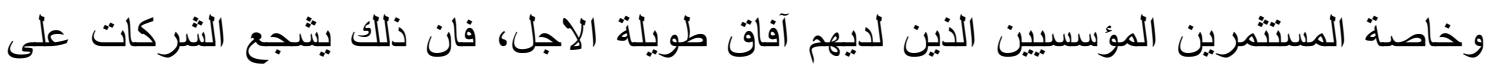

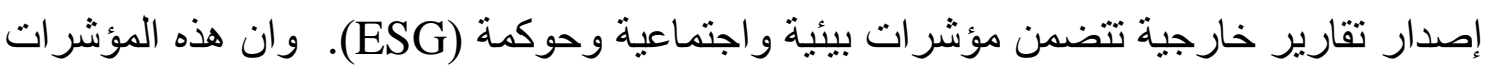
الى جانب التصنيفات أصبحت شائعة على منصات معلومات المستثرين مثل (Bloomberg) و (Eikon)

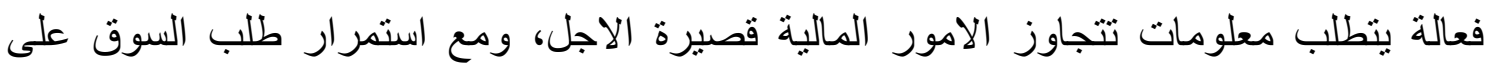

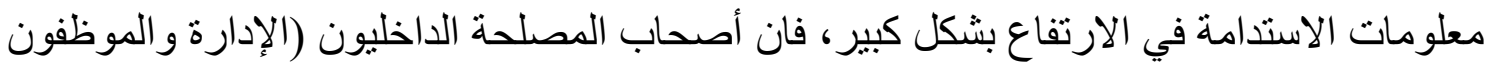

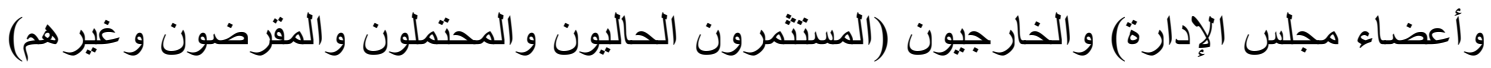

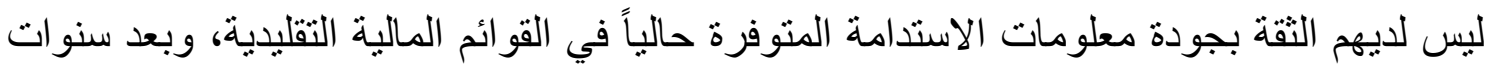
من البحث تم إصدار إطار (COSO) المتكامل للرقابة الداخلية من قبل لجنة المنظمات الر اعية

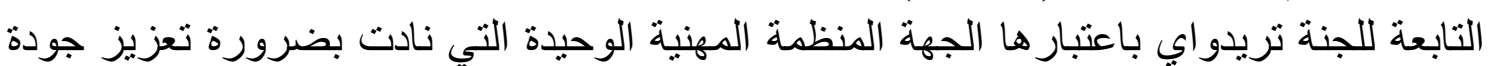

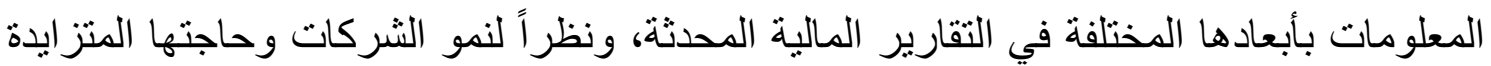
مع أصحاب المصلحة الى معلومات الاستدامة، لابد من تطبيق إطار COSO على عملياتها لتحقيق ذلك (WBCSD, 2013: 4) \& (Littan, 2019: 22). 


\section{المبحث الثالث: الجانب العملي}

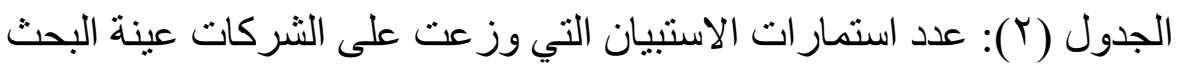

\begin{tabular}{|c|c|c|}
\hline النسبةة & التكرارات & الشركات \\
\hline 20.7 & 18 & شركة نفط الوسط \\
\hline 20.7 & 18 & شركة توزيع المنتجات النفطية \\
\hline 19.5 & 17 & شركة مصافي الوسط \\
\hline 18.4 & 16 & شركة خطوط الانابيب النفطية \\
\hline 20.7 & 18 & الشركة العامة لتعبئة وخدمات الغاز \\
\hline 100.0 & 87 & \\
\hline
\end{tabular}

الجدول من اعداد الباحثتان بالاعتماد على مخرجات البرنامج الاحصائي (SPSS).

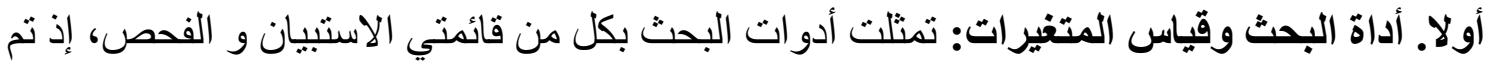

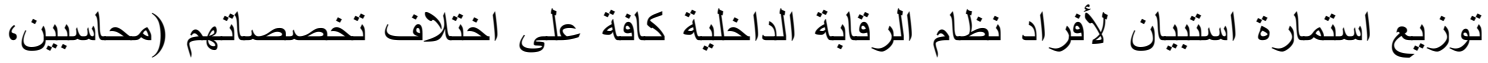
ومهندسين)، وبلغ عدد الاستمار ات الموزعة 100 استمارة، وكان المسترد و الصالح منها للتحليل

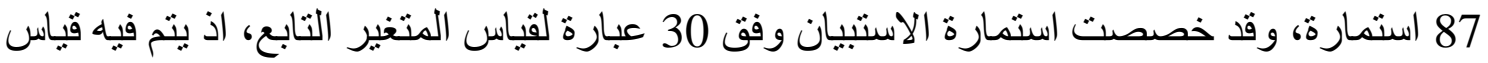
آليات الرقابة الداخلية المعدل بما ينسجم مع مبادئ (COSO) لإعداد تقارير الاستدامة من وجهة

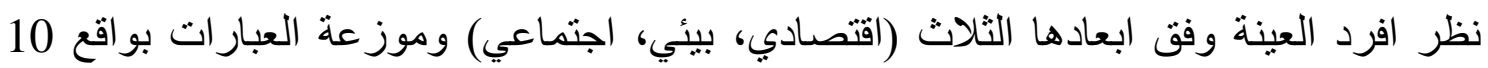
عبار ات للبعد الاقتصادي و 10 عبار ات للبعد البيئي وأخير ا 10 عبار ات للبعد البعد الاجنماعي، وهاعي، وكانت

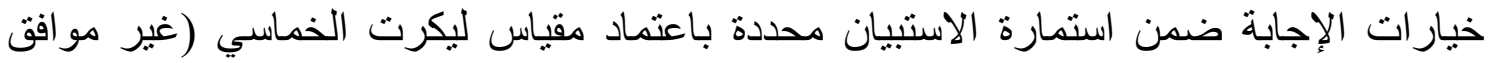

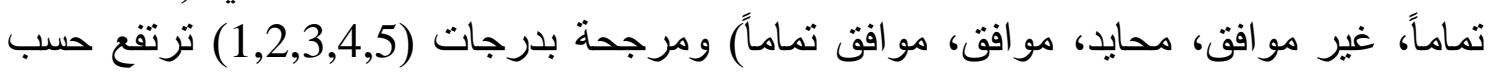

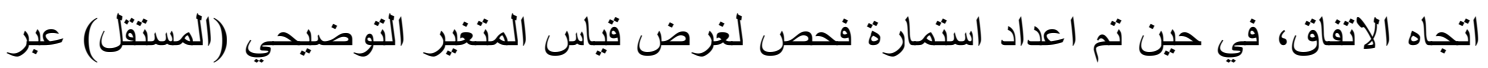
قياس مدى تمسك الثركات عينة البحث بمبادئ (COSO) ضمن نظم و آليات الرقابة الداخلية فيها، وذللك وفق 17 مبدأ، يتم الإجابة عليها بنعم أو لا مرجحة بدرجات (1، 0 0) على التوالي وقد نم

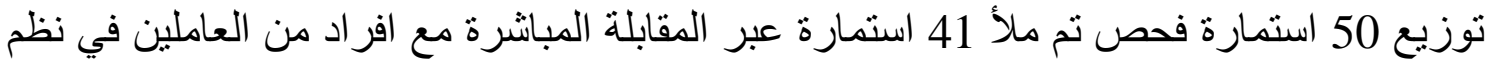

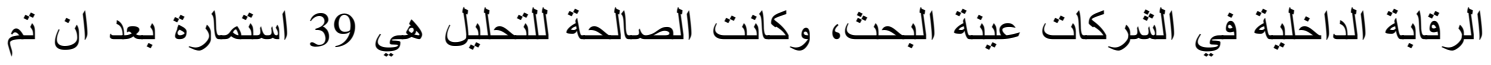

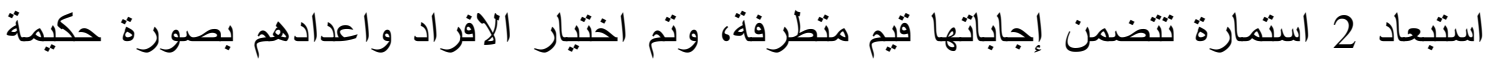
بحسب خبر اتهم. والجدول (ب) يظهر متغيرات البحث وأرقام العبارات في استمارة الاستبيان واستمارة الفحص.

\begin{tabular}{|c|c|c|}
\hline المكونات & \multicolumn{2}{|c|}{ متغيرات البحث } \\
\hline 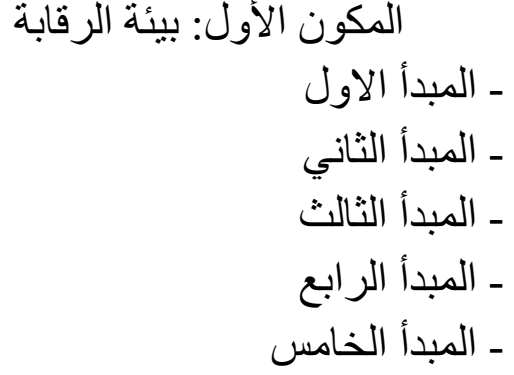 & الطار اليات الرقابة وفق & توضيحي (مستقل) \\
\hline
\end{tabular}




\begin{tabular}{|c|c|c|}
\hline المكونات & البحث & متغير ات \\
\hline 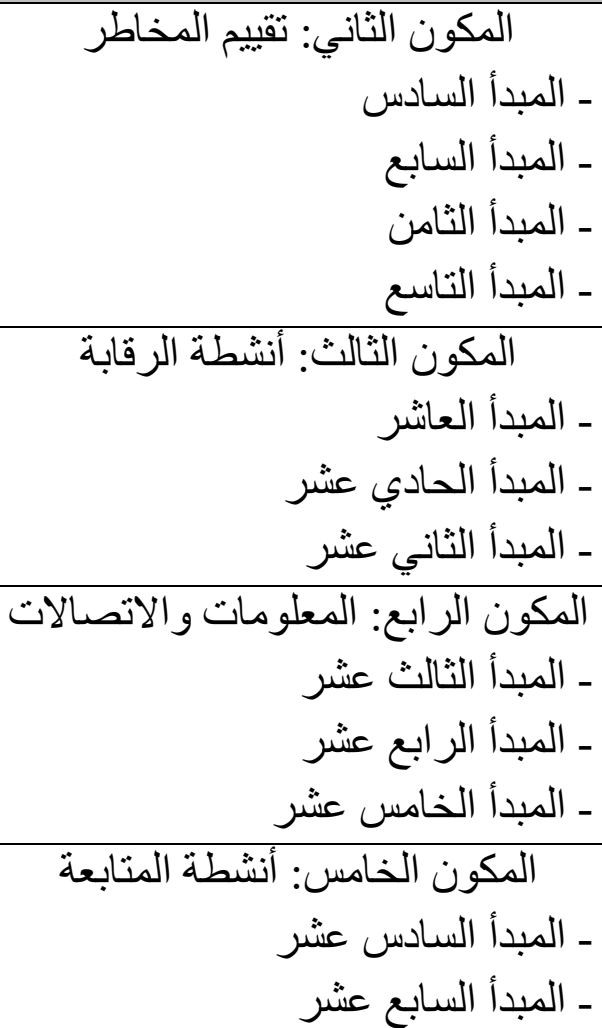 & الطار اليات الرقابة الدابة وفق & توضيحي (مستقل) \\
\hline \multicolumn{3}{|c|}{ الإجمالي } \\
\hline اقتصسادي & \multirow{2}{*}{ تقارير استدامة (COSO) عبرة) } & \multirow[b]{2}{*}{ تابع } \\
\hline اجتماعي & & \\
\hline & & \\
\hline
\end{tabular}

الجدول من اعداد الباحثنان بالاعتماد على مخرجات البرنامج الاحصائي (SPSS).

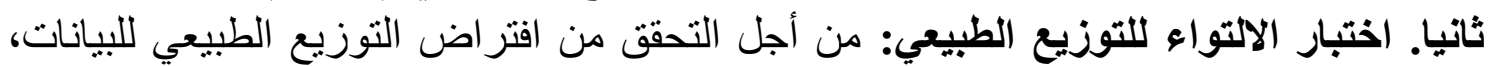

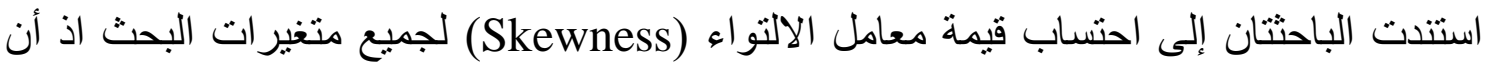

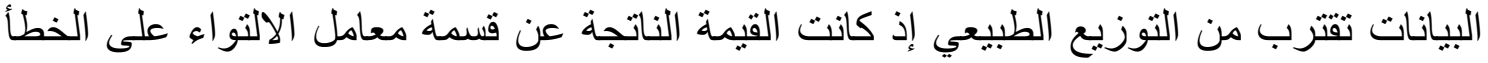

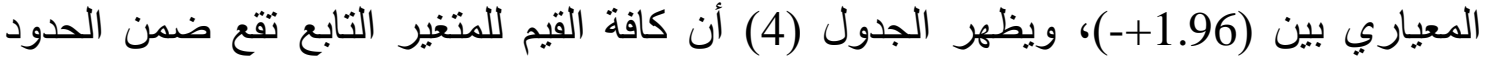
المسموح بها، لذا تتبع البيانات التوزيع الطبيعي ومن ثم يمكن استخدام أدوات واليات التحليل

الجدول (ع): قيم معامل الالتو اء

\begin{tabular}{|c|c|c|c|}
\hline القيمة & الخطأ المعياري & معامل الالتواء & المتغيرات \\
\hline-1.1744 & 0.258 & -0.303 & التابع 1 تقارير الاستدامة وفق (COSO) \\
\hline
\end{tabular}

الجدول من اعداد الباحثتان بالاعتماد على مخرجات البرنامج الاحصنائي (SPSS).

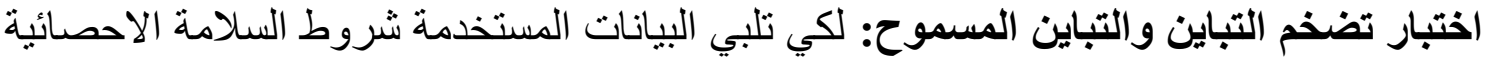
لاختبار معادلات الانحدار الخطي المتعدد، تم استخدام اختبار معامل تضخم التباين (VIF)

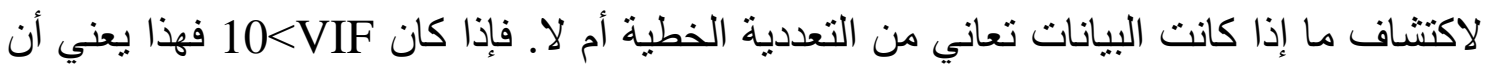


هنالك تعدد خطي عالي، كما أن التباين المسموح (Tolerance) ينبغي ألا يقل عن (0.1) إذ في

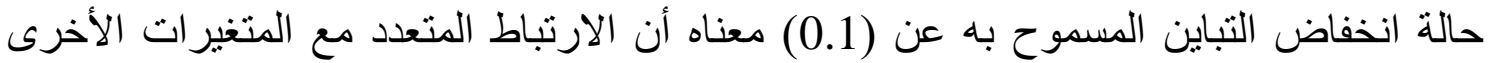
مرتفع مما يزيد من احتمالية تحقق المصاحبة الخطية المتعددة.

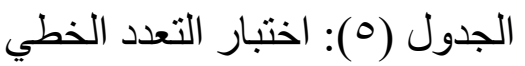

\begin{tabular}{|c|c|c|}
\hline معامل تضخم التباين (VIF) & التباين المسموح & المتغيزات \\
\hline .395 & 2.530 & اليات الرقابة الداخلية وفق إطار (COSO) \\
\hline .393 & 2.544 & المكون الأول: بيئة الرقابة \\
\hline .280 & 3.570 & المكون الثاني: تقييم المخاطر \\
\hline .309 & 3.232 & المكون الثالث: أنشطة الرقابة \\
\hline .262 & 3.810 & المكون الر ابع: المعلومات و الاتصالات \\
\hline .364 & 2.747 & المكون الخامس: أنشطة المتابعة \\
\hline
\end{tabular}

الجدول من اعداد الباحثتان بالاعتماد على مخرجات البرنامج الاحصائي (SPSS).

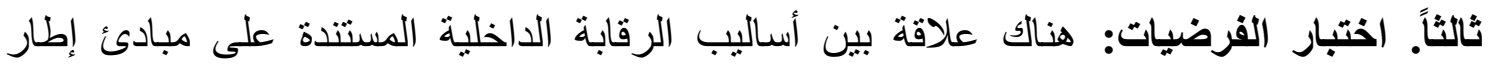

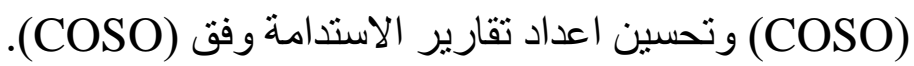

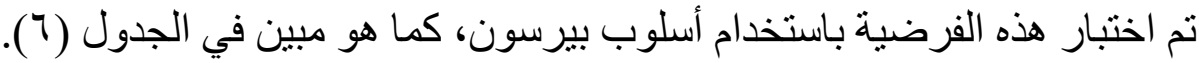

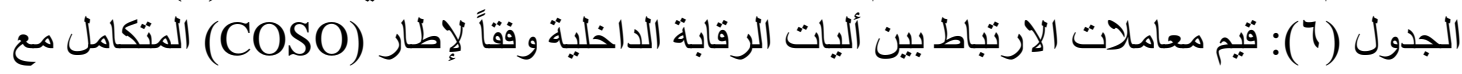

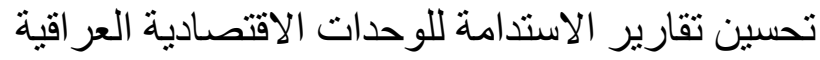

\begin{tabular}{|c|c|c|c|c|c|c|}
\hline أنشطة & والاتصعالات المعات & أنشطة الرقابة & المخاطيم & الرقابية & 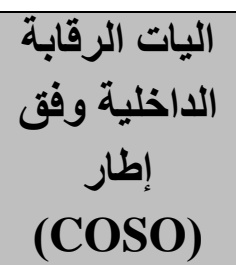 & المتغيرات \\
\hline $0.605^{* *}$ & $0.641^{* *}$ & $0.528^{* *}$ & $0.606^{* *}$ & $0.635^{* *}$ & $0.477^{* *}$ & $\begin{array}{c}\text { الاستدامة وفق } \\
\text { (COSO) }\end{array}$ \\
\hline \multicolumn{6}{|c|}{ وتعني أن الارتباط دال معنوياً عند 1\% } & $* *$ \\
\hline
\end{tabular}

المصدر : الجدول من إعداد الباحثنان بالاعتماد على نتائج التحليل الإحصائي. يلاحظ من مصفوفة العلاقات أن هناك علاقة معنوية بين اليات الرقابة الداخلية المستندة

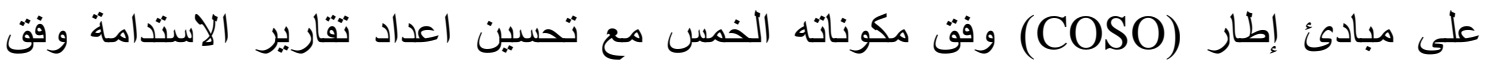
(COSO)

وقد تضمن البحث فرضيتين رئيستين هما:

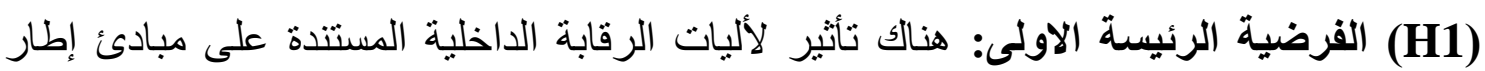

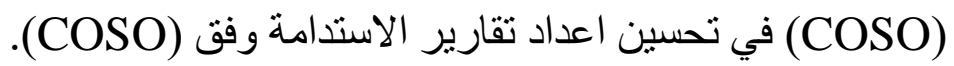

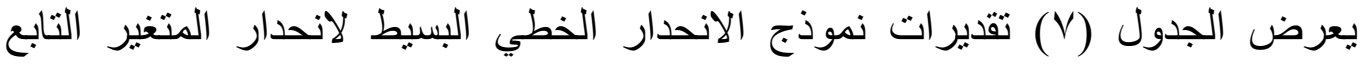
متوسط آر اء العينة حول تحسين اعداد تقارير الاستدامة وفق (COSO) نتيجة لتأثير أليات الرقابة الداخلية المستندة على مبادئ إطار (COSO) كمتغير توضئ أوضيحي. 
الجدول (V): نتائج تحليل تأثثير اليات الرقابة الداخلية وفق إطار (COSO) في تحسين تقارير الاستدامة

\begin{tabular}{|c|c|c|c|c|c|c|}
\hline Durbin-Watson & $\mathrm{R}^{2}$ & $\begin{array}{c}\text { Adjusted } \\
\mathrm{R}^{2}\end{array}$ & $\beta$ & $(\mathrm{T})(\mathrm{Sig})$ & $(\mathrm{F})(\mathrm{Sig})$ & المتغير \\
\hline 1.363 & 0.228 & 0.219 & 0.477 & $\begin{array}{c}5.008 \\
(0.000)\end{array}$ & $\begin{array}{l}25.076 \\
(0.000)\end{array}$ & $\begin{array}{c}\text { الاخلية وفق الرقابة } \\
\text { الطار } \\
\text { (COSO) }\end{array}$ \\
\hline
\end{tabular}

المصدر : الجدول من إعداد الباحثتان بالاعتماد على نتائج التحليل الإحصائي (SPSS).

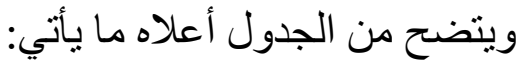
ا. ثبوت معنوية نموذج الانحدار، اذ بلغت قيمة (F) = (25.076)، وهي معنوية عند مستوى

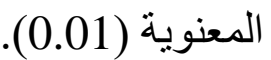

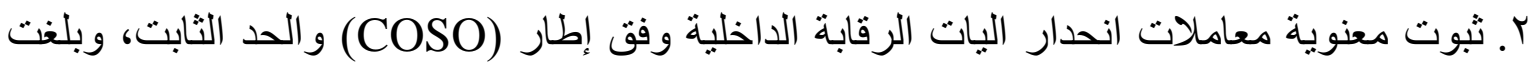

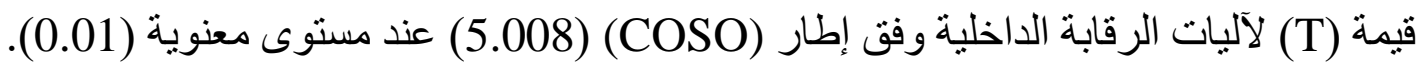

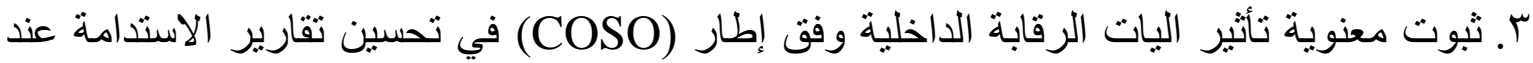

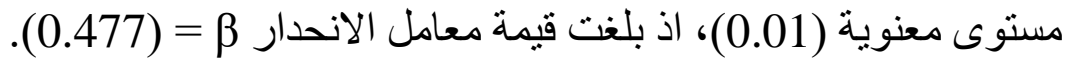

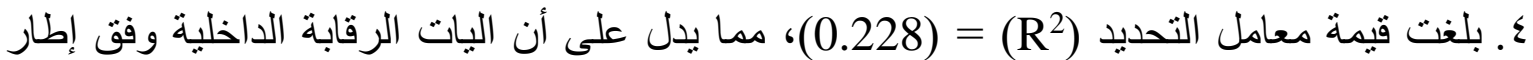

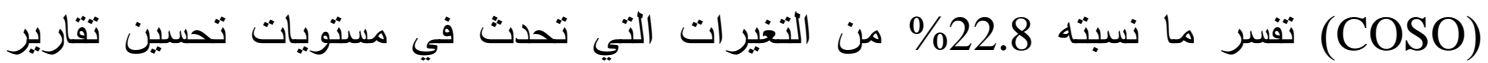

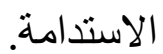

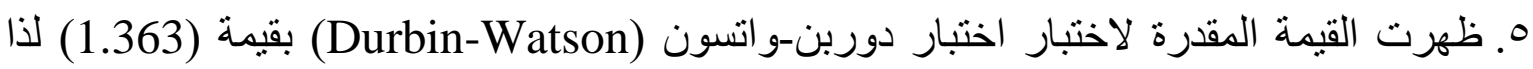

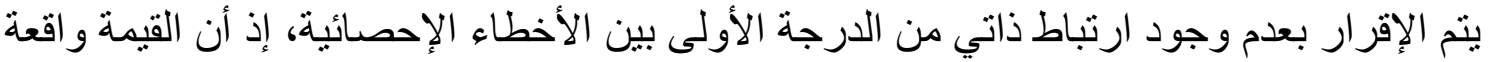

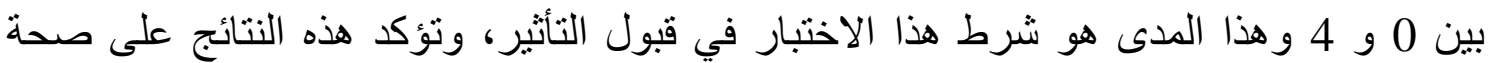

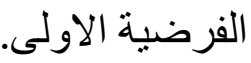
(H2) الفرضية الرئيسة الثانية: هناك تأثير لأليات الرقابة الداخلية المستندة على مبادئ إطار

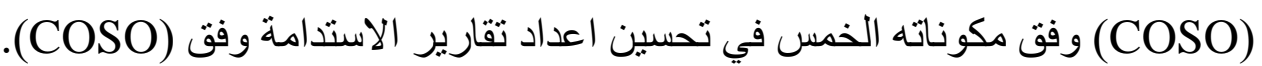
تتفرع هذه الفرضية إلى خمس فرضيات فرعية بحسب المكونات الخمس لإطار (COSO) (COSO) الفرضية الفرعية الأولى: هناك تأثير لبُعد بيئة الرقابة ضمن مبادئ إطار (COS2. 1)

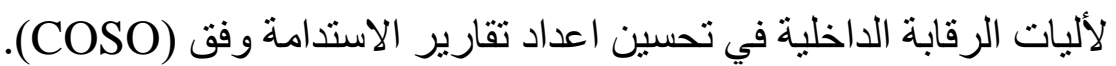

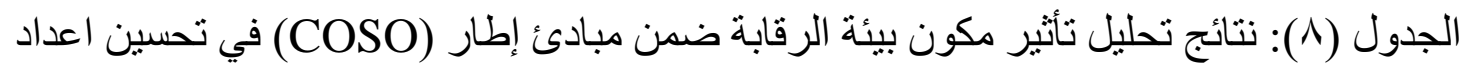
تقارير الاستدامةوفق (COSO)

\begin{tabular}{|c|c|c|c|c|c|c|}
\hline Durbin-Watson & $\mathrm{R}^{2}$ & $\begin{array}{c}\text { Adjusted } \\
\mathrm{R}^{2}\end{array}$ & $\beta$ & $(\mathrm{T})(\mathrm{Sig})$ & $(\mathrm{F})(\mathrm{Sig})$ & المتغير \\
\hline 1.344 & 0.403 & 0.396 & 0.635 & $\begin{array}{c}7.571 \\
(0.000)\end{array}$ & $\begin{array}{l}57.321 \\
(0.000)\end{array}$ & وبيئة الرقابة \\
\hline
\end{tabular}

المصدر : الجدول من إعداد الباحثتان بالاعتماد على نتائج التحليل الإحصائي (SPSS). 


\section{يتضح من الجدول السابق ما يأتي:}

ا ـ ثبوت معنوية نموذج الانحدار، وبلغت قيمة (F) = (57.321)، وهي معنوية عند مستوى المعنوية

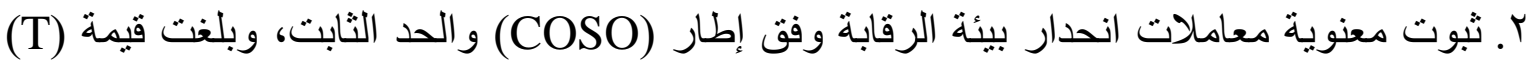

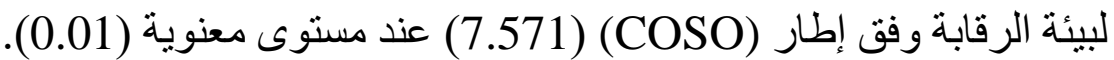

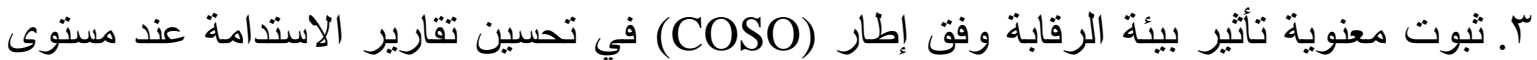

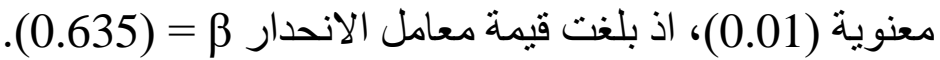

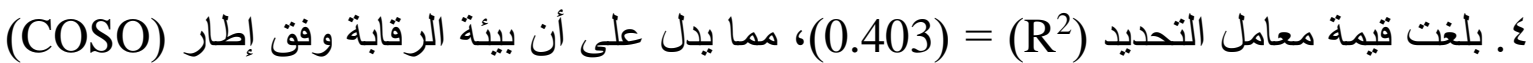
تفسر ما نسبته 40.3\% من التغير ات التي تحدث في مستويات تحسين تقارير الاستدامة.

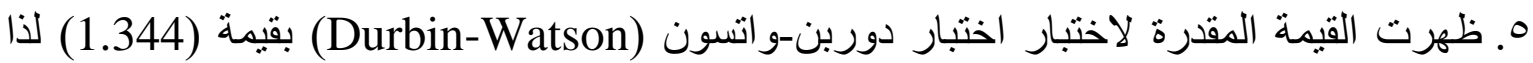

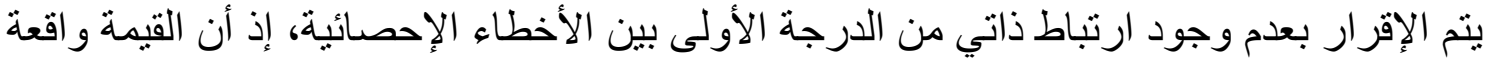

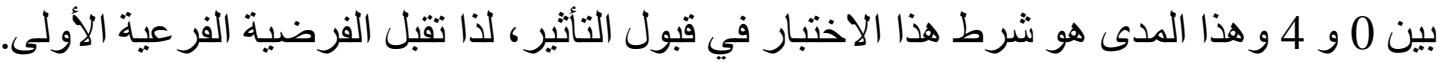

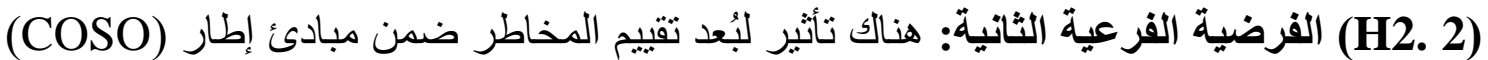

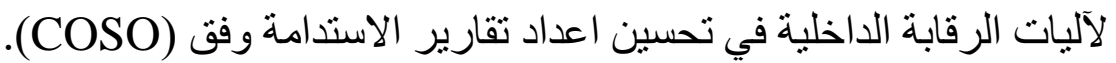

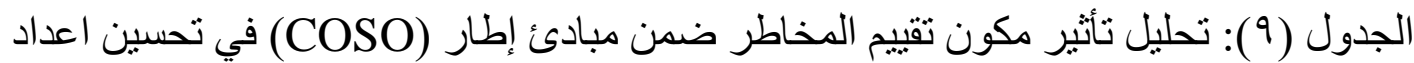
تقارير الاستدامة وفق (COSO)

\begin{tabular}{|c|c|c|c|c|c|c|}
\hline Durbin-Watson & $\mathrm{R}^{2}$ & $\begin{array}{c}\text { Adjusted } \\
\mathrm{R}^{2}\end{array}$ & $\beta$ & $(\mathrm{T})(\mathrm{Sig})$ & $(\mathrm{F})(\mathrm{Sig})$ & $\mathrm{d}$ \\
\hline 1.598 & 0.367 & 0.360 & 0.606 & $\begin{array}{c}7.024 \\
(0.000)\end{array}$ & $\begin{array}{c}49.334 \\
(0.000)\end{array}$ & $\begin{array}{c}\text { (المتغيير } \\
\text { (COSO) }\end{array}$ \\
\hline
\end{tabular}

المصدر: الجدول من إعداد الباحثتان بالاعتماد على نتائج التحليل الإحصائي (SPSS). ويتضح من الجدول أعلاه ما يأتي: ا ـ ثبوت معنوية نموذج الانحدار، وبلغت قيمة (F) = (49.334)، وهي معنوية عند مستوى المعنوية

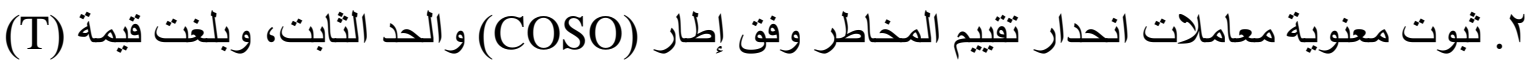
التقييم المخاطر وفق إطار (COSO) (7.024) عند مستوى معنوية (0.01) (0.01).

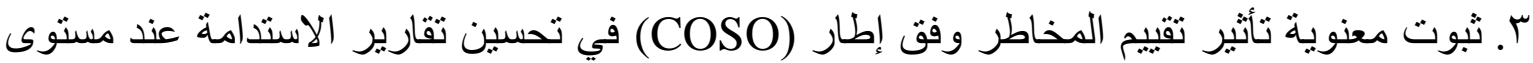

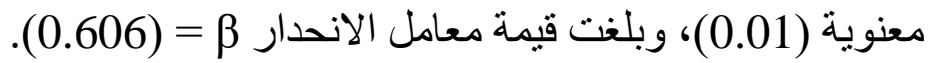

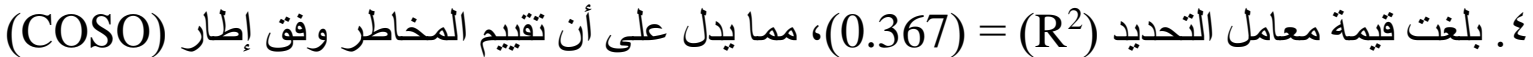
تفسر ما نسبته 36.7\% من التغير ات التي تحدث في مستويات تحسين تقارير الاستدامة.

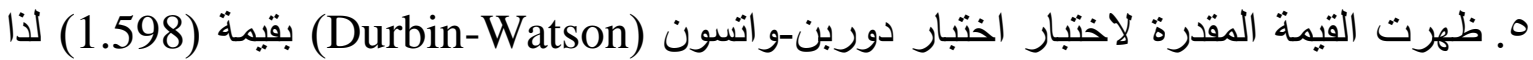

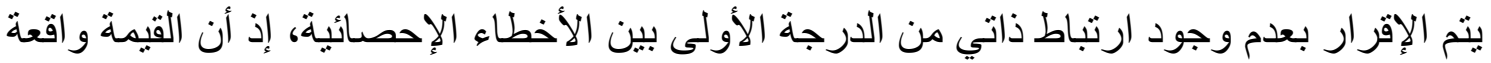

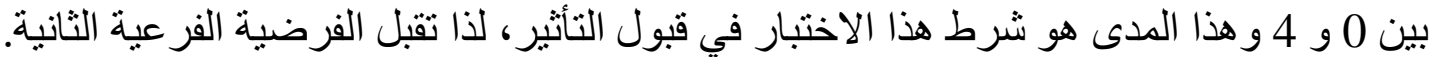
(H2. 3)

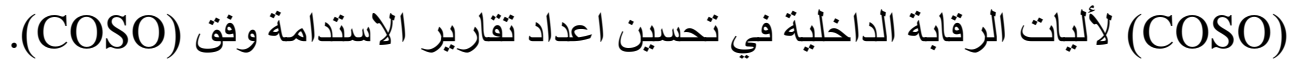


الجدول (• (): تحليل تأثير مكون انشطة الرقابة ضمن مبادئ إطار (COSO) في تحسين اعداد تقارير الاستدامة وفق (COSO)

\begin{tabular}{|c|c|c|c|c|c|c|}
\hline Durbin-Watson & $\mathrm{R}^{2}$ & $\begin{array}{c}\text { Adjusted } \\
\mathrm{R}^{2}\end{array}$ & $\beta$ & $(\mathrm{T})(\mathrm{Sig})$ & $(\mathrm{F})(\mathrm{Sig})$ & المتغير \\
\hline 1.478 & 0.279 & 0.270 & 0.528 & $\begin{array}{c}5.734 \\
(0.000)\end{array}$ & $\begin{array}{l}32.884 \\
(0.000)\end{array}$ & 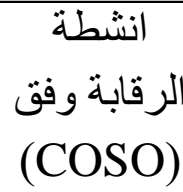 \\
\hline
\end{tabular}

المصدر : الجدول من إعداد الباحثتان بالاعتماد على نتائج التحليل الإحصائي (SPSS).

$$
\text { ويتضح من الجدول أعلاه ما يأتي: }
$$

ا ـ ثبوت معنوية نموذج الانحدار، وبلغت قيمة (F) = (32.884)، وهي معنوية عند مستوى المعنوية

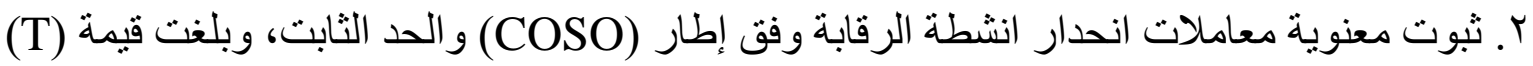

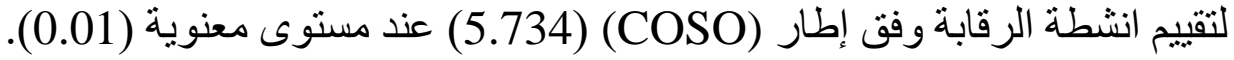

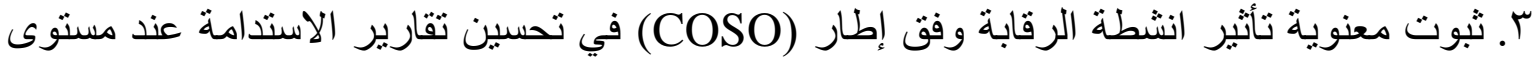

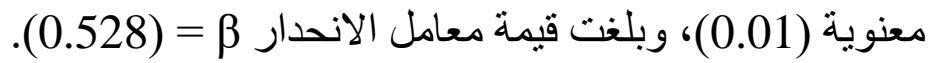

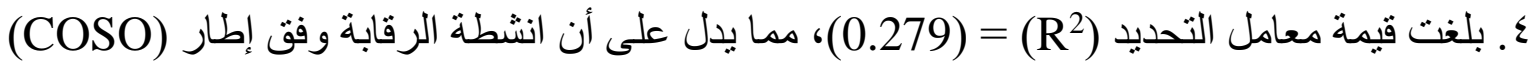
تفسر ما نسبته 37.9\% من التغير ات التي تحدث في مستويات تحسين تقارير الاستدامة.

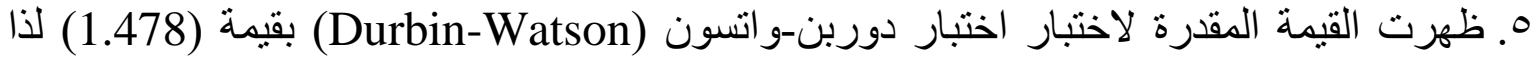

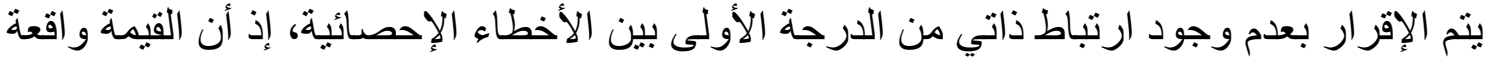

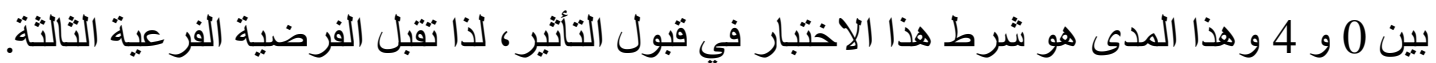

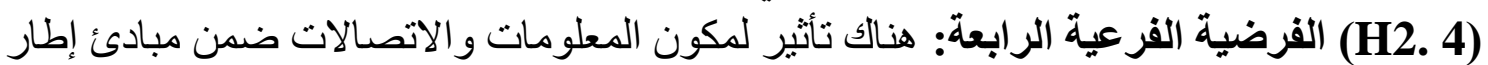

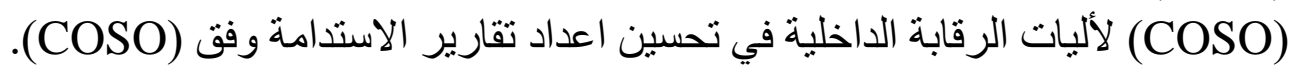

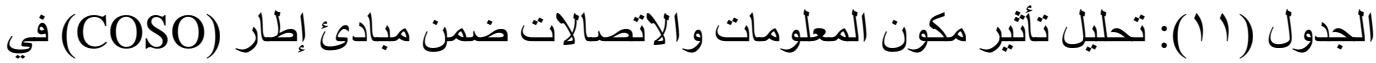
تحسين اعداد تقارير الاستدامة وفق (COSO)

\begin{tabular}{|c|c|c|c|c|c|c|}
\hline Durbin-Watson & $\mathrm{R}^{2}$ & $\begin{array}{c}\text { Adjusted } \\
\mathrm{R}^{2}\end{array}$ & $\beta$ & $(\mathrm{T})(\mathrm{Sig})$ & $(\mathrm{F})(\mathrm{Sig})$ & المتغير \\
\hline 1.522 & 0.411 & 0.404 & 0.641 & $\begin{array}{c}7.699 \\
(0.000)\end{array}$ & $\begin{array}{l}59.270 \\
(0.000)\end{array}$ & والاتصالات \\
\hline
\end{tabular}

الهصدر : الجدول من إعداد الباحثتان بالاعتماد على نتائج التحليل الإحصائي (SPSS).

$$
\text { ويتضح من الجدول أعلاه ما يأتي: }
$$

ا ـ ثبوت معنوية نموذج الانحدار، وبلغت قيمة (F) = (59.270)، وهي معنوية عند مستوى المعنوية

r. ثبوت معنوية معاملات انحدار المعلومات و الاتصالات وفق إطار (COSO) (COSO) و الحد الثابت، وبلغت قيمة (T) للمعلومات و الاتصالات وفق إطار (COSO) (7.699) عند مستوى معنوية (0.01). 
r. ثبوت معنوية تأثثر المعلومات والاتصالات وفق إطار (COSO) في تحسين تقارير الاستدامة عند

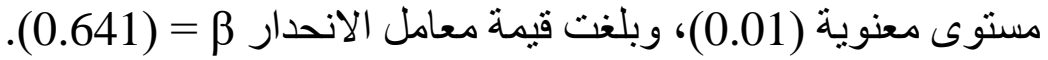

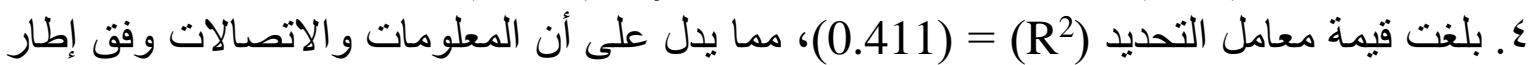
تفسر ما نسبته 41.1\% من التغيرات التي تحدث في مستويات تحسين تقارير (COSO) الاستدامة.

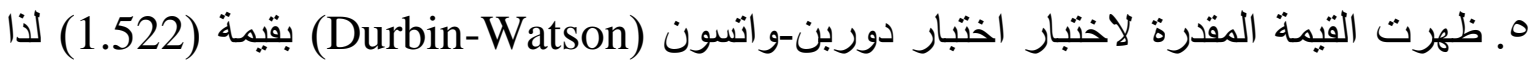

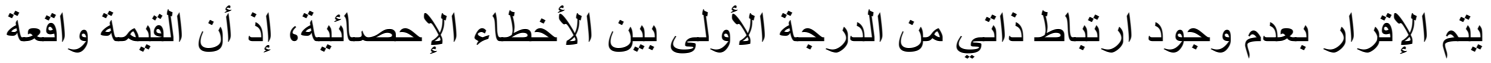

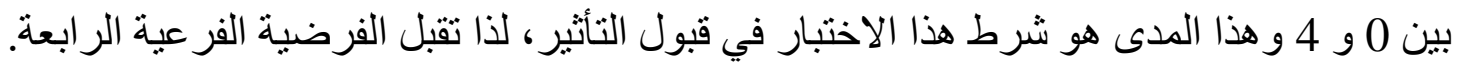
(H2. 5)

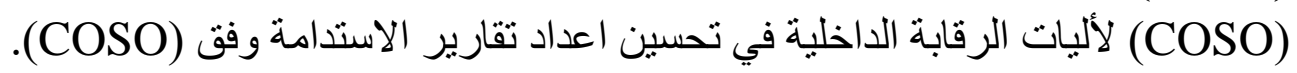

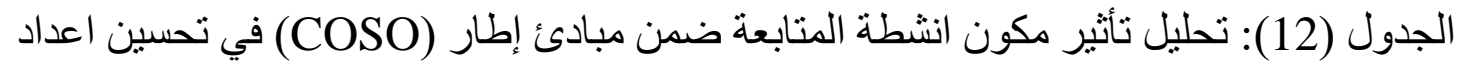
تقارير الاستدامة وفق (COSO)

\begin{tabular}{|c|c|c|c|c|c|c|}
\hline Durbin-Watson & $\mathrm{R}^{2}$ & $\begin{array}{c}\text { Adjusted } \\
\mathrm{R}^{2}\end{array}$ & $\beta$ & $(\mathrm{T})(\mathrm{Sig})$ & $(\mathrm{F})(\mathrm{Sig})$ & المتغيرة \\
\hline 1.596 & 0.366 & 0.359 & 0.605 & $\begin{array}{c}7.011 \\
(0.000)\end{array}$ & $\begin{array}{c}49.148 \\
(0.000)\end{array}$ & $\begin{array}{c}\text { المتابعة وفن } \\
\text { (COSO) }\end{array}$ \\
\hline
\end{tabular}

المصدر : الجدول من إعداد الباحثتان بالاعتماد على نتائج التحليل الإحصائي (SPSS). ويتضح من الجدول أعلاه ما يأتي: ا ـ ثبوت معنوية نموذج الانحدار، وبلغت قيمة (F) = (49.148)، وهي معنوية عند مستوى المعنوية r. ثبوت معنوية معاملات انحدار انشطة المتابعة وفق إطار (COSO) والحد الثابت، وبلغت قيمة

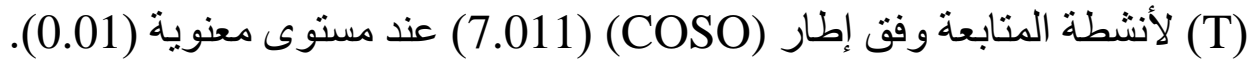

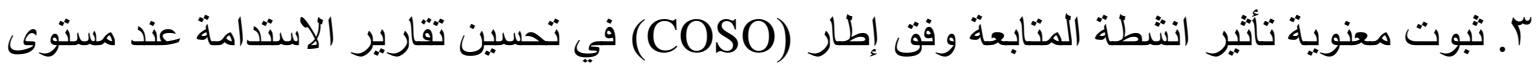

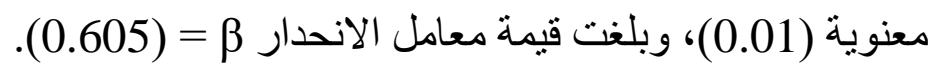

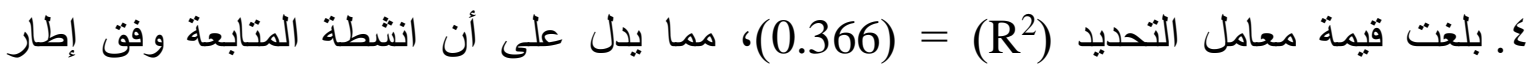
تفسر ما نسبته 36.6\% من التغيرات التي تحدث في مستويات تحسين تقارير (COSO) الاستدامة.

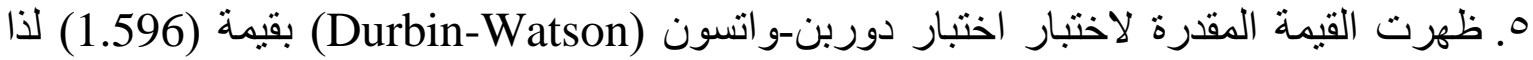

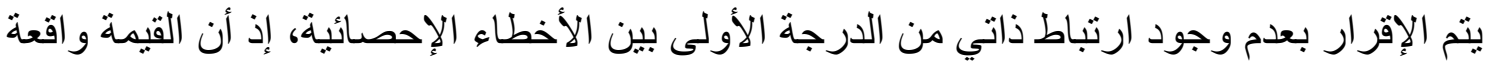
بين 0 و 4 و هذا المدى هو شرط هذا الاختبار في قبول التأثير ، لذا تقبل الفرضية الفر عية الخامسة. وبناءً على قبول الفرضيات الفرعية الخمس أعلاه لذا تقبل الفرضية الرئيسة الثانية.

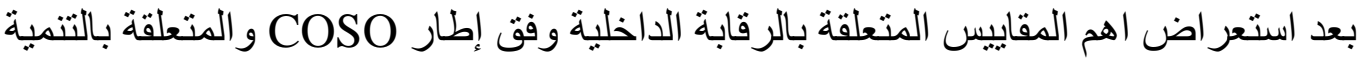
المستدامة بالاستناد الى مكونات إطار COSO ومقارنتها مع النتائج التي تم الحصول علئيها اتضح للباحثتين ان هناك تأثثر للرقابة الداخلية وفقاً لإطار COSO المتكامل في تحسين تقارير الاستدامة 


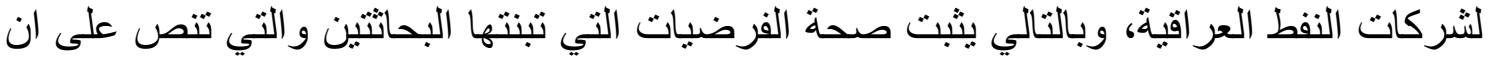

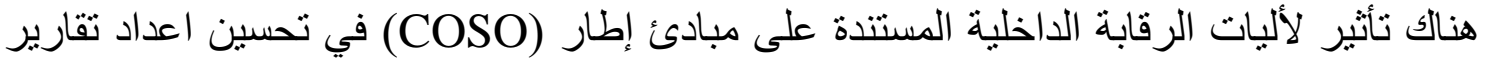
الاستدامة وفق (COSO)

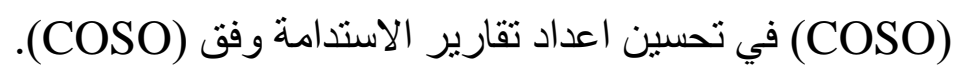
المبحث الرابع: الاستتناجات والتوصيات

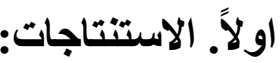

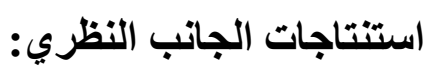

ا . يوجد قصور في الافصاح عن التنمية المستدامة ضمن القوائم المالية التقليدية، وذلك لوجود قيود محددة عند إعدادها. r. ان استخدام الاطر الحديثة في تصميم نظام الرقابة الداخلية للوحدات الاقتصادية ومنها إطار

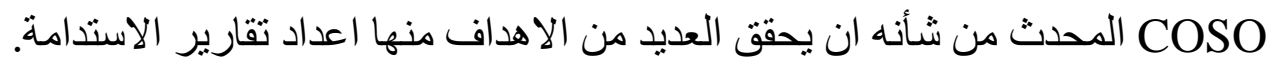

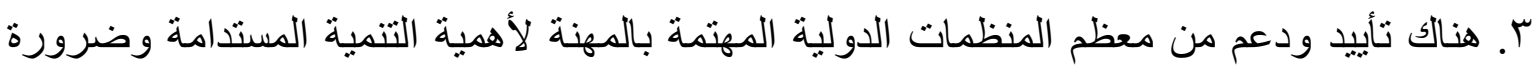

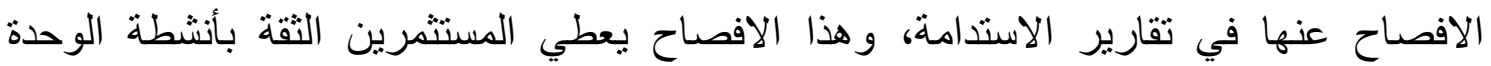

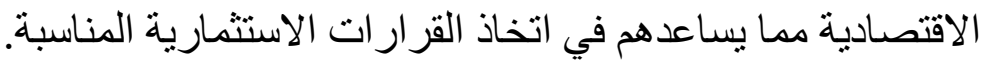

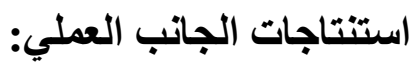
ا ـ نختلف مستويات تبني إطار (COSO) في أساليب الرقابة الداخلية باختلاف الثركات عينة البنات البحث.

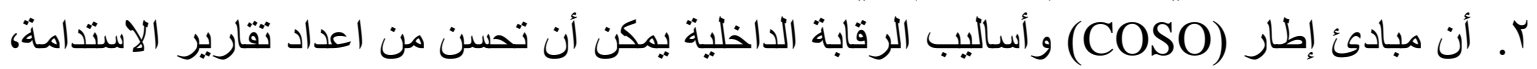

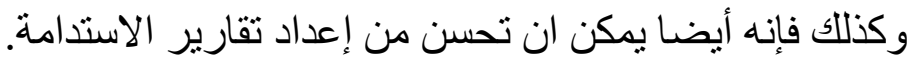

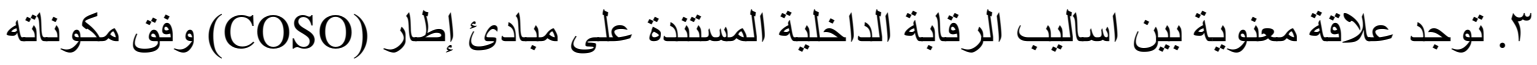

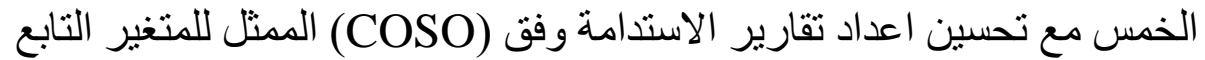

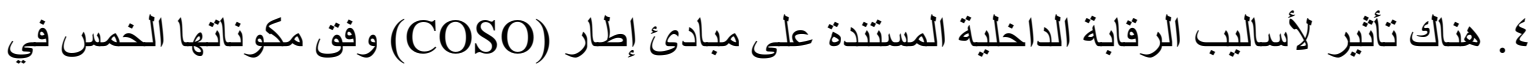

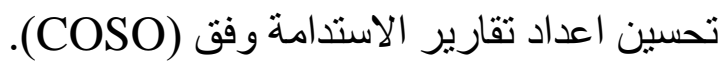

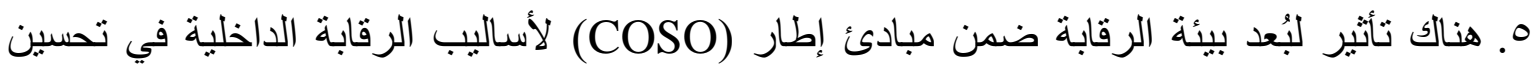

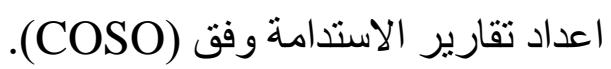

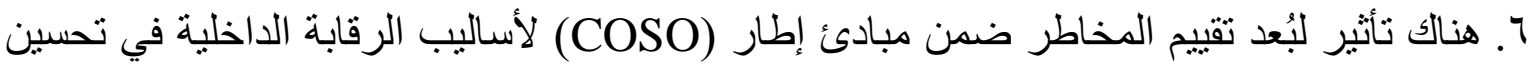

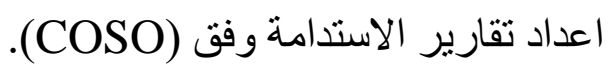

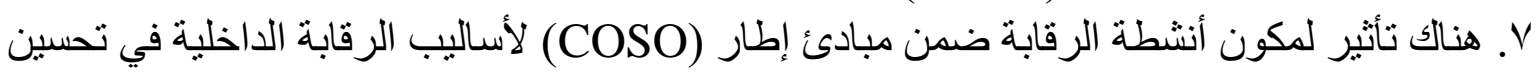

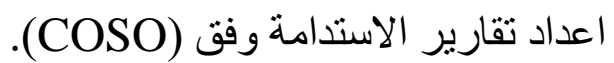

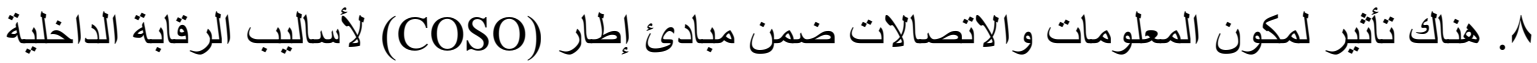

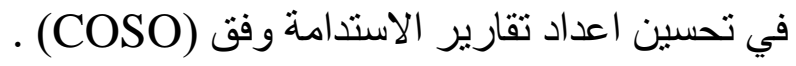

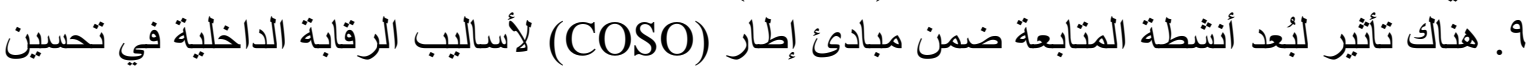

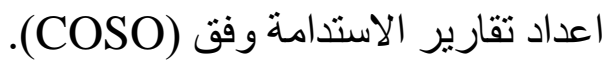

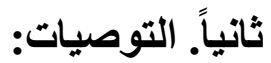

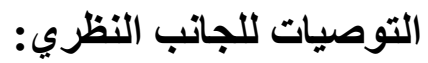

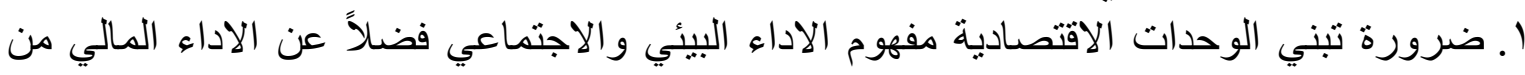

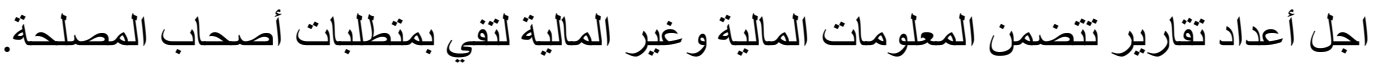


r. ينبغي صياغة انموذج خاص للتنمية المستدامة يتناسب مع الامكانيات المتاحة ويلبي احتياجات

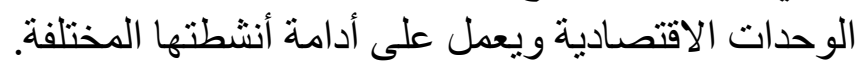

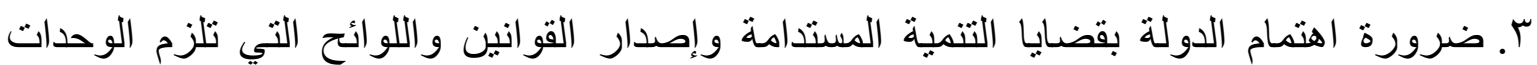

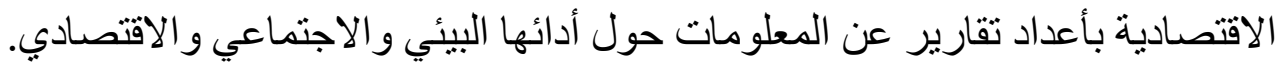
ا. التركيز على مكون بيئة الرقابة واعطاءه المزيد من الاهتمام لما له من تأثير على الرقابة الداخلية

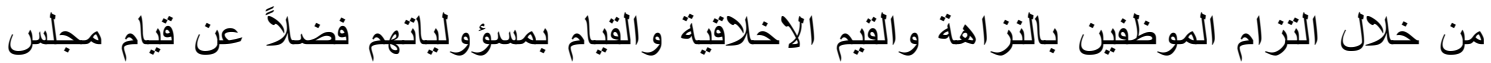

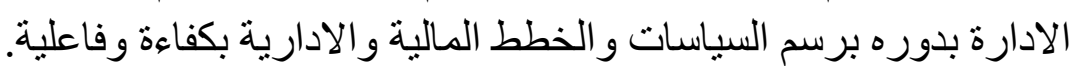
ץ. توجيه اهتمام الثركات عينة البحث بضرورة اجر اء تقييم دقيق وشامل للمخاطر التي من الممكن ان تحد من انشطتها او تؤثر سلباً في اعمالها. r. ضرورة اهتمام ادارة الثركات بمكون انشطة الرقابة و العمل على تطبيق اجر اءات معالجة البيانات و التفويضات و الفصل بين المهام وغير ها من الانشطة التي تعمل على تحسين فاعلية انشطة الرقابة

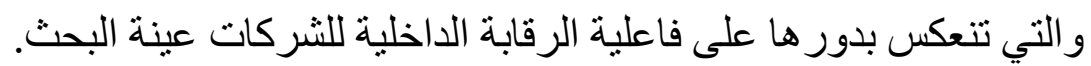

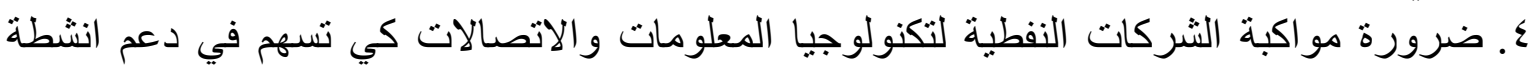

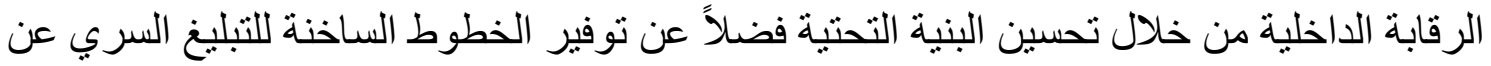
المخالفات من خلال توفير ارقام خاصة. ه. توجيه الاهتمام نحو مكون انشطة المتابعة للتحقق مما إذا كانت الرقابة الداخلية ملائمة وفعالة من

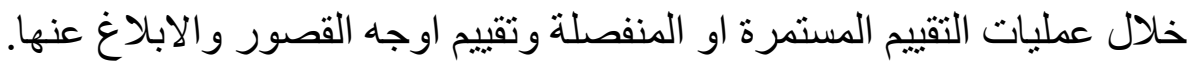
المصادر

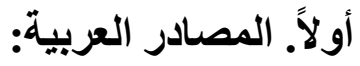

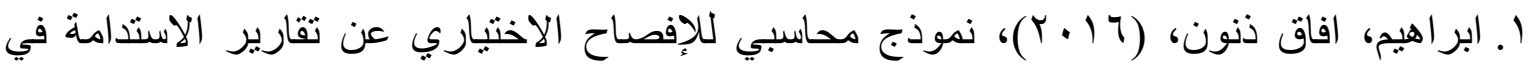

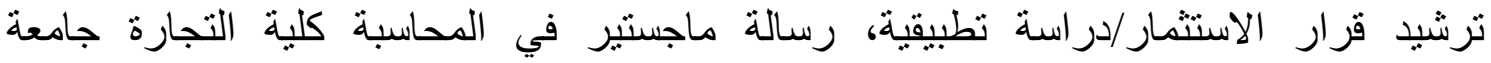

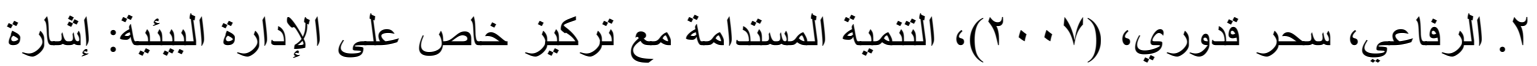

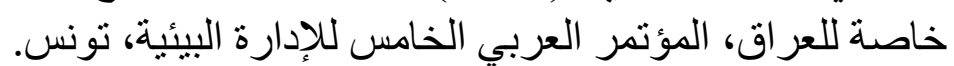

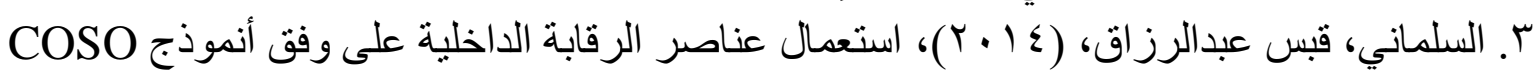
لتقويم الأداء البيئي في الوحدات الاقتصادية، رسالة دبلوم عالي، المعهد العالي للمحاسبين القانونيين، العراق.

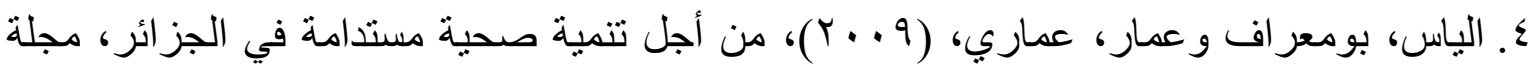

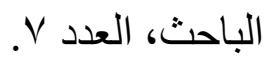

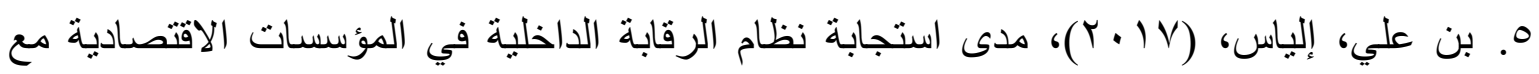
إطار COSO: دراسة حالة مؤسسة مطاحن الواحات، رسالة ماجستير غير منشورة، كلية العلوم

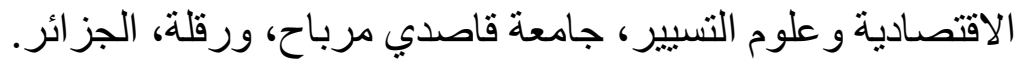

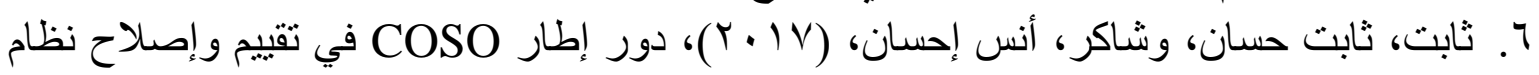

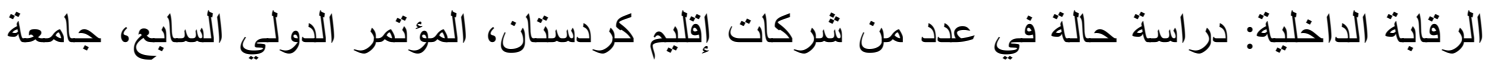
جرمو، السليمانية، العراق. 
V. شرف، أحمد عبدالقادر، (10 (Y))، مدخل مفترح لتأكيد تقارير استدامة الثركات المصرية

و انعكاسه على ادر الك اصحاب المصالح، در اسة مقارنة، اطروحة دكتور اه، كلية التجارة، جامعة

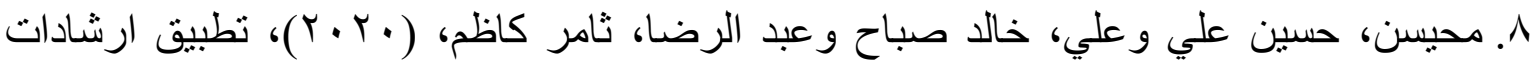

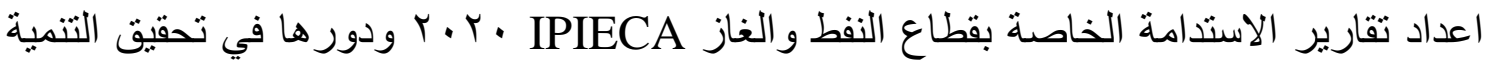

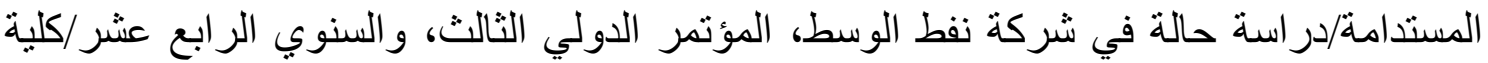
الادارة والاقتصاد/الجامعة المستتصرية.

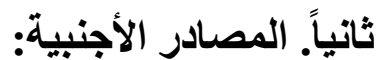

1. Arens, Alvin A., et al., (2012), Auditing and Assurance Services: An Integrated Approach, $14^{\text {th }}$ edition, Prentice Hall.

2. Bini, Laura, and Bellucci, Marco, (2020), Integrated Sustainability Reporting Linking Environmental and Social Information to Value Creation Processes, Springer Nature Switzerland AG.

3. COSO (1992), Internal Control-Integrated Framework, Committee of Sponsoring Organizations of the Treadway Commission, COSO Report.

4. COSO (2013), Internal Control-Integrated Framework: Executive Summary, Committee of Sponsoring Organizations of the Treadway Commission.

5. Dinapoli, Thomas P., (2007), Standards for Internal Control in New York State Government, Available online at:

6. Gardetti, M. Á., (2019), Sustainability: Is It Redefining the Notion of Luxury?. Springer Nature.

7. Grosskuth, J. and Rotmans, J., (2005), The Scene Model: Getting Grip on Sustainable Development in Policy Making Environment, Development and Sustainability, 7(1).

8. Idowu, Samuel O., (2015), Social Audit in the Supply Chains Sector. In: Idowu, Samuel O., and Rahim, Mia Mahmudur (eds.), Social Audit Regulation Development, Challenges and Opportunities, pp. (187-200), Springer International Publishing Switzerland .

9. Kinkela, Katherinem (2015)m United States Accounting Firms Respond to COSO Advice on Social Audit, Sustainability Risk and Financial Reporting. In: Idowu, Samuel O., and Rahim, Mia Mahmudur (eds.), Social Audit Regulation Development, Challenges and Opportunities, pp. (59-77), Springer International Publishing Switzerland.

10. Lee, Ki-Hoon and Herold, David M., (2018), Cultural Relevance in Environmental and Sustainability Management Accounting (EMA) in the Asia-Pacific Region: A Link between Cultural Values and Accounting Values Towards EMA Values. In: Lee, KiHoon, and Schaltegger, Stefan (eds.), Accounting for Sustainability: Asia Pacific Perspectives, pp. (11-38), Springer International Publishing AG.

11. Littan, S., (2019), The COSO Internal Control Framework and Sustainability Reporting. The CPA Journal, 89(7), 22-26.

12. Lutz, Julia, (2015), Committee of Sponsoring Organizations of the Treadway Commission: Internal Control-Integrated Framework in special consideration of the 
changes in the new edition 2013, MSc. Thesis, University of Applied Sciences, Germany.

13. Mammatt, J., (2009), Integrated Sustainability Reporting and Assurance. CIS Corporate Governance Conference, Sandton Convention Centre, Johannesburg, South Africa.

14. Moeller, R. R., (2007), COSO enterprise risk management: understanding the new integrated ERM framework. John Wiley \& Sons.

15. Morelo, N., (2011), The importance of internal control in the brazilian public administration. The George Washington University-School of Business and Public Management. Minerva Program Spring.

16. Provasi, R., and Riva, P., (2015), The Updated COSO Report 2013, Journal of Modern Accounting and Auditing, 11(10), 487-498.

17. Thabit, T., (2019, April), Determining the Effectiveness of Internal Controls in Enterprise Risk Management based on COSO Recommendations. In International Conference on Accounting, Business Economics and Politics.

18. Uzun, Sertan, (2017), Evaluating COSO Model As An Internal Auditing Structure in Botaş, E-MBA, School of Social Sciences, Istanbul Bilgi University, Turkey .

19. Uwadiae, Oduware, (2015), COSO-An Approach to Internal Control Framework, Financial Reporting, Deloitte.

20. Zsoka, Agnes, and Vajkai, Eva, (2018), Corporate Sustainability Reporting: Scrutinizing the Requirement of Comparability, Transparency and Reflection of Sustainability Performance. Journal of Society and Economy in Central and Eastern Europe.

21. WBCSD, (2013), Controlling Non-Financial Reporting, World Business Council for Sustainable Development, Conches-Geneva, Switzerland.

\section{الملحق الاول}

استبانة إعداد تقارير الاستدامة المعدل وفقاً لتوصيات إطار COSO

\begin{tabular}{|c|c|c|c|c|c|c|}
\hline تماماً & اتفق & محايد - & 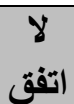 & لا لاماً & الفقرة & $ت$ \\
\hline \multicolumn{7}{|c|}{ المحور الاول: الاقتصادي } \\
\hline & & & & & و المجنمع و الوحدة على تضمئ في ثقافة الوحدة الإقتصادية ذات الصلة بالبيئة & 1 \\
\hline & & & & & بالبيئة والمجتمع والإدارة العليا الوعمة الكافي بالمخاطر ذات الصلة & $r$ \\
\hline & & & & & 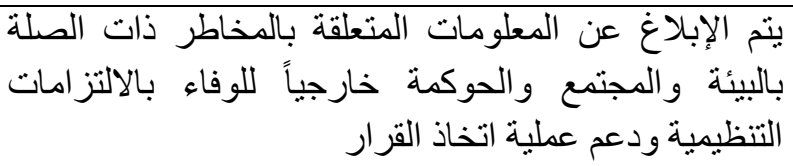 & $r$ \\
\hline & & & & & 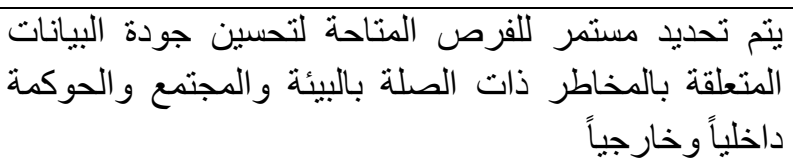 & $\varepsilon$ \\
\hline & & & & & 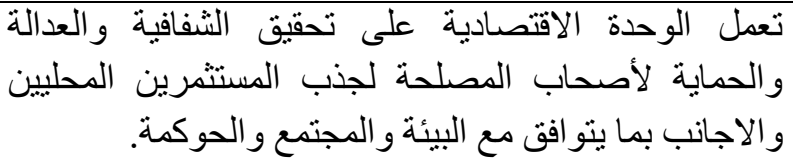 & 0 \\
\hline
\end{tabular}




\begin{tabular}{|c|c|c|c|c|c|c|}
\hline تماماً & اتفق & محايد & اتفق & لا اتفقي & الفقرة & ت \\
\hline & & & & & 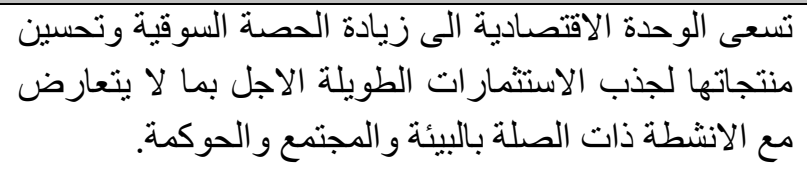 & 7 \\
\hline & & & & & 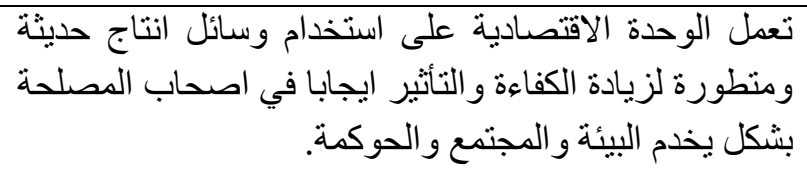 & V \\
\hline & & & & & و التأثثر وضع درات والتبعات عملية خلق رأس القيمة ونموذج الأعمال لفهم المدى القصير & $\wedge$ \\
\hline & & & & & 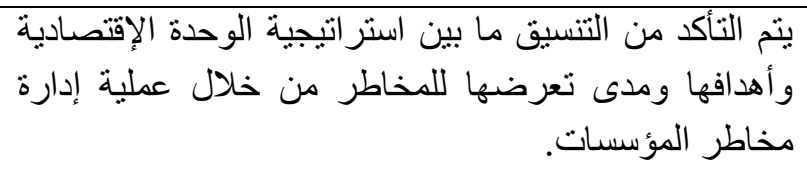 & 9 \\
\hline & & & & & و يتم تحليل الأسباب الجوهرية للمخاطر ذات الصلة بالبيئة & 1. \\
\hline \multicolumn{7}{|c|}{ المحور الثاني: البيئي } \\
\hline & & & & & 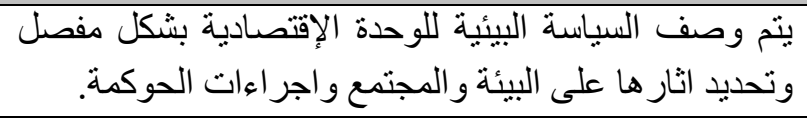 & 11 \\
\hline & & & & & للتمد وضع الانبعاثات الضارة خطط طويلة الأجل للوحدة الإقتصادية & IT \\
\hline & & & & & نظام وإجراءات الحوكمة العليا السياسات البيئية المتوافقة مع منطلبات & سו \\
\hline & & & & & 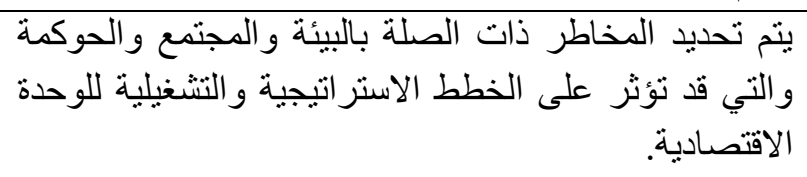 & $1 \varepsilon$ \\
\hline & & & & & 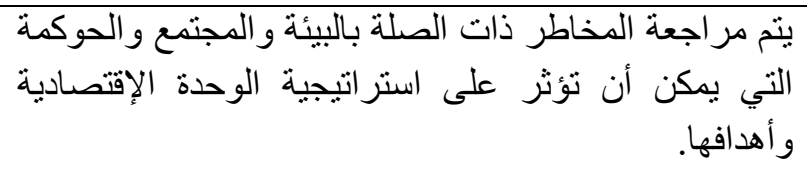 & 10 \\
\hline & & & & & 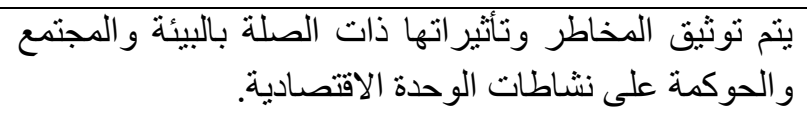 & 17 \\
\hline & & & & & 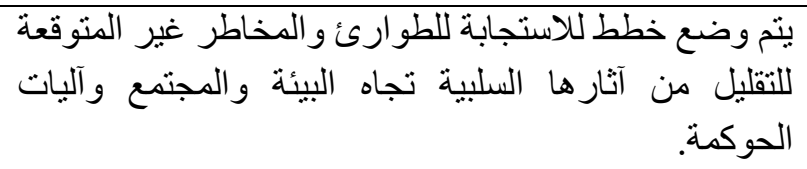 & IV \\
\hline & & & & & 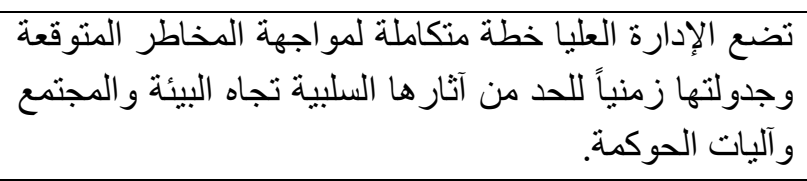 & 11 \\
\hline & & & & & 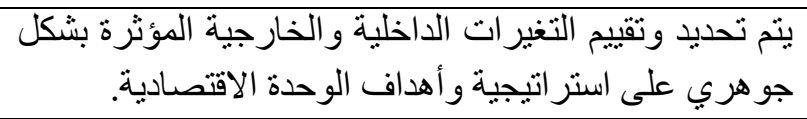 & 19 \\
\hline & & & & & 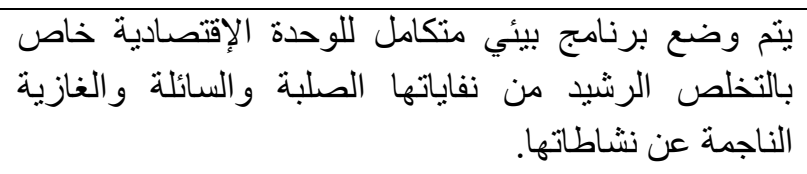 & $r$. \\
\hline
\end{tabular}




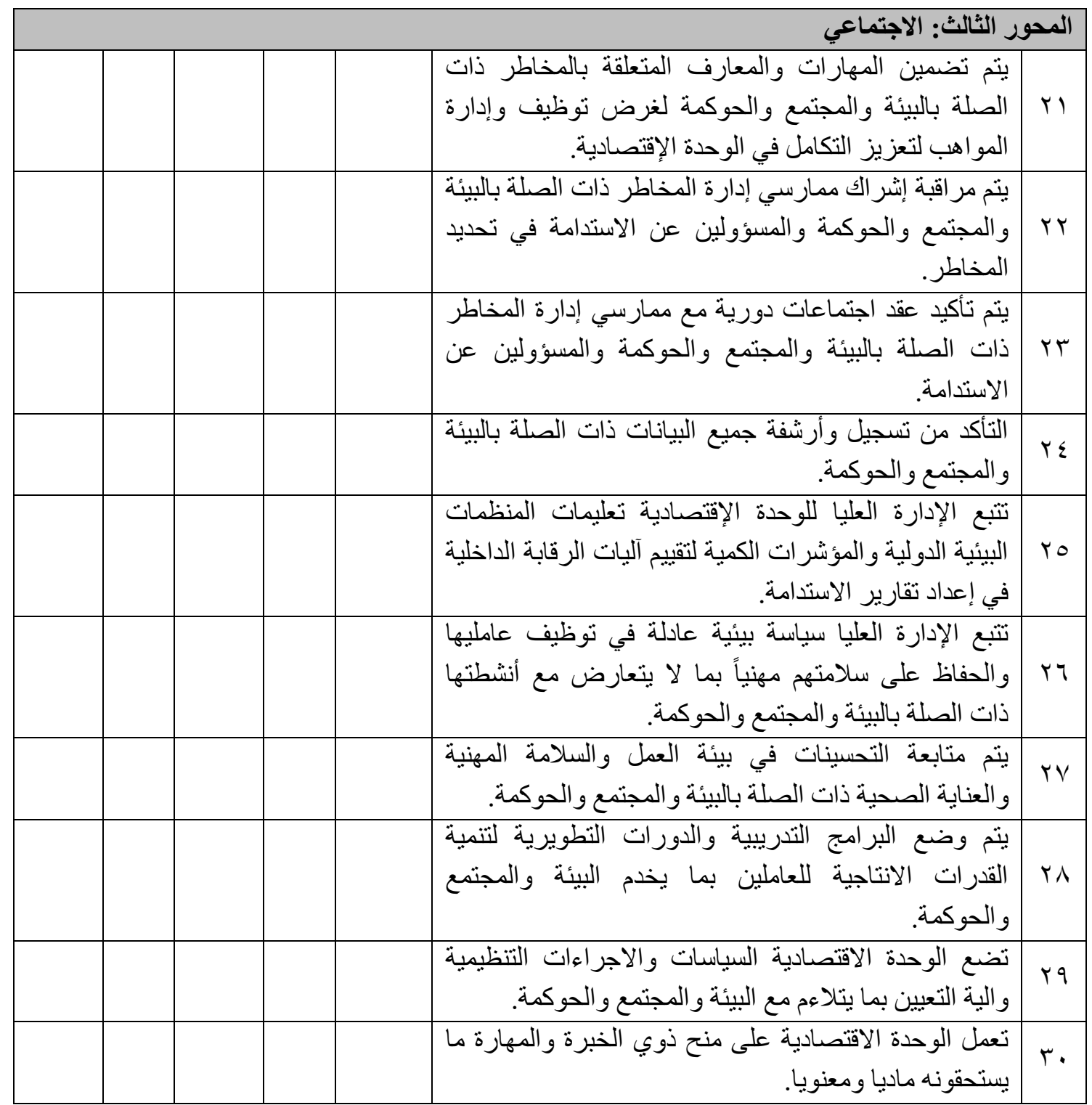

قائمة لفحص الرقابة الداخلية باستخدام نقاط التركيز لمبادئ مكونات الرقابة الداخلية وفق إطار COSO. الملحق الثاني

قائمة لفحص الرقابة الداخلية باستخدام مبادئ مكونات الرقابة الاخلية وفق إطار COSO

\begin{tabular}{|c|c|c|}
\hline & & ر الأول: بيئة الرقابة \\
\hline كلا & نعم & 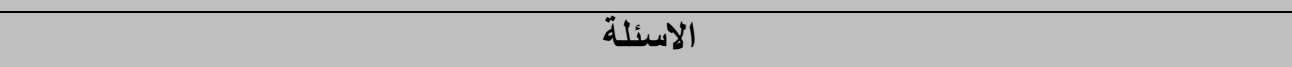 \\
\hline & & المبدأ الاول: ابداء الوحدة الاقتصادية التز ام بالنز اهة والقيم الاخلاقية. \\
\hline & & الداخلية. الثاني: يوضح مجلس الإدارة الاستقلال عن الإدارة ويمارس الرقابة على تطوير و أداء الرقابة \\
\hline & & 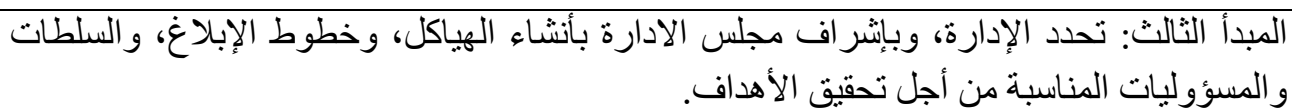 \\
\hline & & 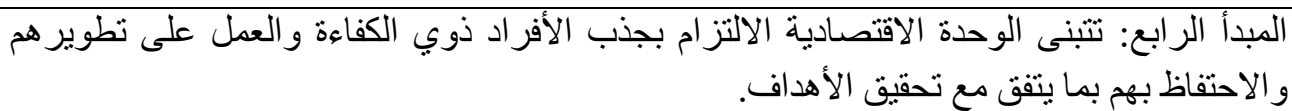 \\
\hline & & الأهبداف الخامس: تحمل الوحدة الاقتصادية الأفراد مسؤولية الرقابة الداخلية في السعي لتحقيق \\
\hline
\end{tabular}




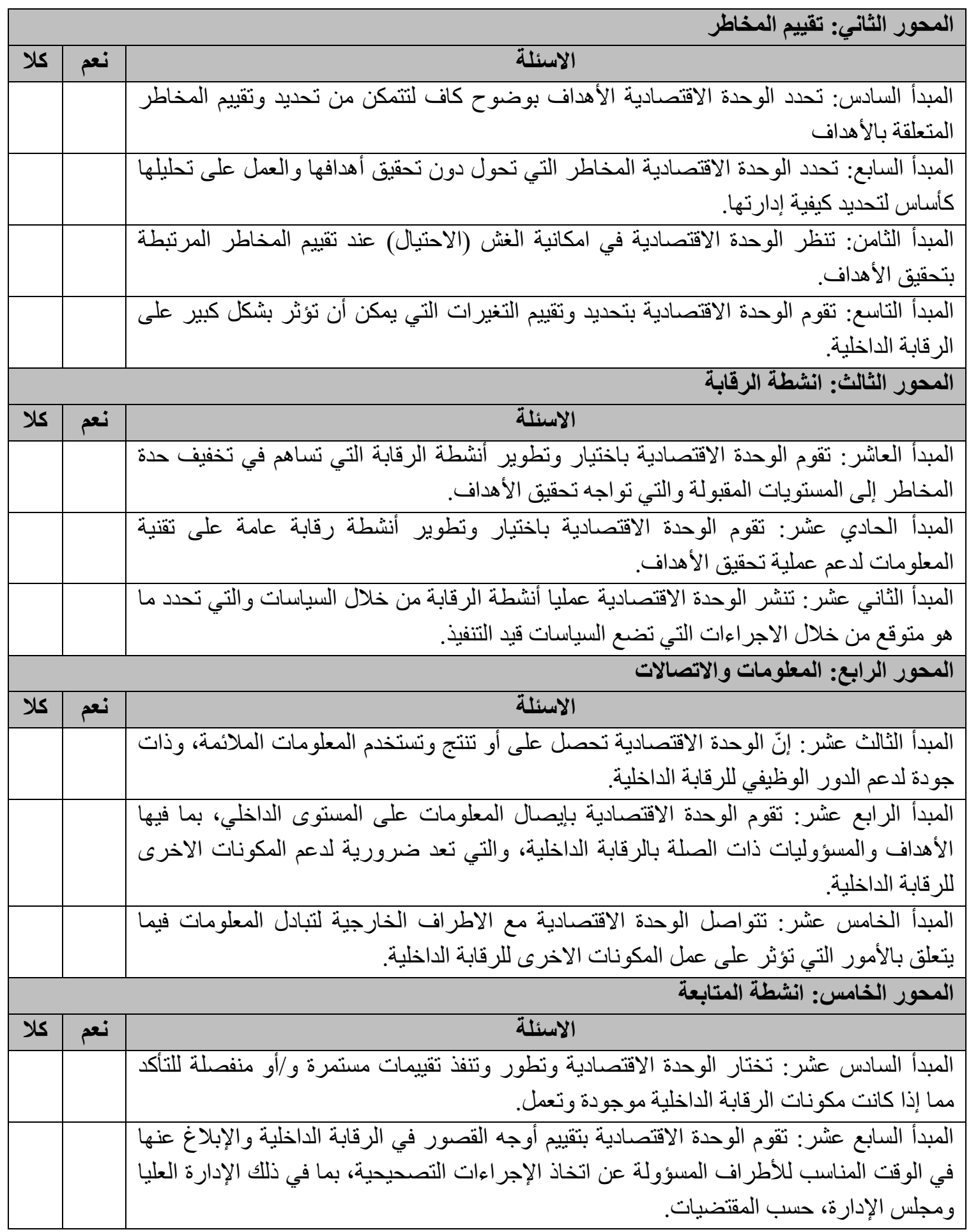

